\title{
THE AIR COOLING OF PETROL ENGINES.
}

\author{
By A. H. GIbsoN, D.So.; Professor of Engineertara, \\ Untvrratty College, Dundee.
}

(1) THE theory of the air cooling of the petrol engine has been investigated in a very comprehensive paper read before this Institution by Mr. F. W. Lanchester in 1915.* It is not intended to deal with this side of the question in the present paper, which records some of the results of experimental work on air cooled engines carried out by the author and his colleagues between the years 1916-1919.

This work was carried out almost entirely on aero engines having cylinder sizes somewhat larger than those adopted in automobile practice. It is, however, hoped that the results may be of some use in the design of air cooled engines suitable for car work, and that the paper may serve to supplement that of Mr. Lanchester.

(2) Laws of air cooling.-The cooling surfaces of the modern air cooled cylinder almost invariably take the form of a series of fins, though in some special cases cooling spikes may be used with advantage over certain portions of the cylinder. A large number of tests have been made to determine the rate of heat dissipation from such surfaces, with results which show that for wind speeds between 20 miles per hour and 60 miles per hour the heat loss is sensibly proportional to the mean temperature-difference between the fin surface and the incoming air, and to the 0.73 power of the wind speed. For a given material the heat dissipation is sensibly independent of the roughness of the surface. Different materials have slightly different dissipation coefficients. A steel surface appears to give somewhat greater heat dissipation than an aluminium or a copper surface, the difference being, however, onlyabout 5 to 10 per cent. The dissipation from cast aluminium fins appears to be improved by a coating of suitable stoving enamel, the difference between the enamelled and plain fins being about. 10 per cent.

* See Pruc. I.A.E., Vol. X., p. 59. 
Over the range of cylinder sizes usual in practice, the dissipation coefficient is sensibly independent of the cylinder diameter.

A large number of tests have been made to determine the heat loss from finned cylinders in a parallel air blast, with results which indicate that, for copper fins, this heat loss is given by-

$$
\sigma=\left(0.0247-0.0054\left(l^{0.8} / p^{0.4}\right)\right) \mathrm{V}^{0.73}
$$

in Centigrade heat units per sq. $\mathrm{ft}$. per min. per degree Centigrade of difference between the mean temperature of the fins and that of the incoming air.

Here $l$ is the length of the fins in inches.

$p$ is the pitch in inches, measured from surface to surface of adjacent fins.

$\mathrm{V}$ is the wind speed in miles per hour.

This relationship has been deduced from tests on cylinders having diameters ranging from 1.25 in. to 3.75 in., with fin lengths ranging from $0.63 \mathrm{in}$. (16 mm.) to $1.62 \mathrm{in.}(41 \mathrm{~mm}$.), and with pitches ranging from 0.1575 in. ( $4 \mathrm{~mm}$.) to 0.75 in. $(19 \mathrm{~mm}$.). Where the fins are of tapering section, the value of $p$ should bes taken at the mean height of the fin.

(3). Shape and size of fins.-The fin which gives the maximum heat-loss per unit of weight is one having slightly concave surfaces and a sharp tip. It may be shown, however, that a plain triangular fin is.only very slightly less efficient. The best proportions for such a fin depend on the conductivity of the material and on the wind speed. For a speed of 40 miles per hour, Table $I$. shows the best proportions for such fins of aluminium alloy (conductivity $=0.38$ C.G.S. units) and steel (conductivity $=0.10$ C.G.S. units) and also for copper fins (conductivity $=0.90$ C.G.S. units).

TABLE: I.

\begin{tabular}{|c|c|c|c|c|c|c|c|c|}
\hline \multicolumn{2}{|c|}{ Bottom breadth "B" $\mathrm{cm}$. } & 0.025 & 0.05 & $0 \cdot 1$ & 0.2 & 0.3 & 0.4 & 0.5 \\
\hline & Aluminium & & - & $2 \cdot 0$ & $2 \cdot 9$ & 3.5 & $4 \cdot 1$ & 4.5 \\
\hline $\begin{array}{c}\text { Length } \\
\mathrm{cm} .\end{array}$ & Steel & & $\cdots$ & $1 \cdot 1$ & $1 \cdot 5$ & $1 \cdot 8$ & $2 \cdot 1$ & $2 \cdot 3$ \\
\hline & Copper & $1 \cdot 6$ & $2 \cdot 3$ & $\mathbf{3} \cdot \mathbf{3}$ & $4 \cdot 6$ & .. & .. & \\
\hline
\end{tabular}


If such a fin be truncated until the tip breadth is one-fifth of the bottom breadth, the lengths become 80 per cent of those given above. The heat dissipation is about 0.88 times and the weight 0.96 times as great as for the complete triangular fin.

Since the heat dissipated from a fin of given shape varies directly as the length of the fin, while the weight varies as the square of the length of the fin, other things being equal, cooling fins should be as short as possible, a large number of short thin fins being used in preference to a smaller number of longer and thicker fins. While in practice this is to be borne in mind, many other factors besides that of weight have an important bearing on the best size of fin to be adopted. Thus, in a thin steol cylinder, or in a cylinder of cast iron or cast aluminium alloy, the circumferential ribs add greatly to the strength and resistance to distortion. Comparatively deep and heavy fins have a greater effect in this direction than a larger number of similar but smaller fins giving the same cooling. Again, as the number of fins is increased, the pitch is correspondingly diminished. This diminution in pitch reduces the air flow between the fins to an extent which may, with very small pitches, render the fins practically useless for cooling purposes.

In a cylinder of cast iron or of aluminium alloy, foundry difficulties put a definite limit to the minimum pitch of the fins. On the barrel itself a somewhat smaller pitch may be adopted than on the head, or the barrel fins may be turned out of the solid if desired. On account of the complicated form of the eylinder head and ports, however, it is impossible to machine their cooling fins, and the length of many of the cores necessitates the pitoh being made fairly large. The minimum practical pitch of fin for such cylinders, having a diameter of from 4 in. to 6 in., is about 8 to $9 \mathrm{~mm}$. or about $5 / 16$ in. Foundry difficulties also prevent the casting of a fin having a tip less than about $0.5 \mathrm{~mm}$. in thickness, or a root thickness less than about $l / 10$, so that an aluminium fin 1 in. long would not have a root thickness less than 0.1 in.

For steel cylinders with fins turned out of the solid, the pitch may, with advantage, be cut down to about $\frac{1}{4}$ in. on a cylinder of 3 in. or so in diameter, but there appears to be little to be gained by reducing the pitch beyond this point.

(4) Variation of cooling with density of air. The cooling intensity of an air blast depends on the weight of air brought into contact with the cooling surfaces in unit time. In the case of an 
aero engine, the density of the air varies considerably with the height. The weight involved in cooling is proportional to $\rho \mathrm{V}$, and the heat dissipated from a finned surface is proportional to $(\rho \nabla)^{0.73}$. In the case of an automobile engine the variation in density may, in general, be neglected except for units designed for operation at high altitudes.

(5) Heat to cylinder walls and piston.-The amount of heat transmitted from the working fluid to the walls and piston of an internal combustion engine depends upon a number of factors, including:--

(a) the design of the cylinder,

(b) the strength of the working mixture,

(c) the spark adrance,

(d) the compression ratio,

(e) the fuel used,

(f) the speed of rotation,

(g) the size of the cylinder.

The bearing of these various factors will be considered at a later stage.

Since the heat transmission from the fluid to the walls during its most important stage, i.e. during and directly after explosion, is largely due to radiation, and is therefore probably approximately proportional to $\left(\mathbf{T}_{g}{ }^{4}-\mathbf{T}_{w}{ }^{4}\right)$ where $\mathbf{T}_{g}$ and $\mathbf{T}_{w}$ are the absolute temperatures of the gas and the walls, any such difference of wall temperature as is likely to exist in practice between an air cooled engine and a water cooled engine can have little effect on the rate of heat transmission. As a matter of fact, such measurements as have been made show that the differences in wall temperature, piston temperature, and exhaust valve temperature, between a well designed air cooled cylinder and the corresponding water cooled cylinder are small, and that unless the water cooling system is well arranged, the air cooled cylinder may be, and often is, actually the cooler of the two.

In view of this, since it is much easier to obtain a measurement of the heat flow through the cylinder walls of a water cooled engine than through those of an air cooled engine, where such heat-loss can only be determined from the heat balance sheet by differences, such determinations have usually been made on water cooled engines. It is true that, since the water jacket surrounds the exhaust port or a short length of the exhaust pipe, the heat measured in this way includes a proportion of heat which should, 
correctly, be included in the heat of the exhaust, but as in both cases this heat has ultimately to be dissipated, in the one case by the radiator and in the other case by the cooling fins, this forms the essential heat flow so far as cooling problems are concerned.

Tests of a water cooled engine may be carried out either with or without an air blast. In the case of a large multi-cylinder engine an air blast is usual in order to keep the valve springs and exhaust pipe moderately cool and to remove the exhaust gases. In this case, a very appreciable amount of heat is dissipated from the surfaces of the water jackets and crank case, and the heat actually passing into the jacket water from the working fluid is greater by this amount than that computed from a measurement of the weight and inlet and outlet temperatures of the jacket water. By carrying out duplicate tests with the same wind speed but with different jacket water temperatures, it is, however, possible to determine the heat actually passing through the walls in such a case, and this may be checked by the results of tests with no cooling: wind. In the latter case a small experimental correction for radiation from the surface is necessary.

Figures are available from a number of tests on engines of various types, from which these values have been obtained, and the essential data of these tests are given in Table II. For convenience, the heat passing into the walls and piston has been expressed as a fraction of the b.h.p., $42 \cdot 42$ B.Th.Us. per minute being taken as the equivalent of $1 \mathrm{~h} . \mathrm{p}$. The heat passing through the walls is denoted by the symbol A.

TABLE II.

\begin{tabular}{|c|c|c|c|c|c|c|c|c|}
\hline 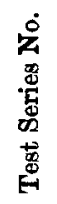 & Engine. & 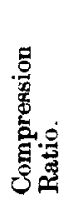 & 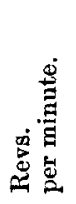 & م: & 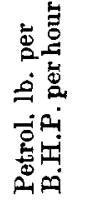 & 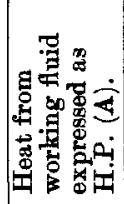 & 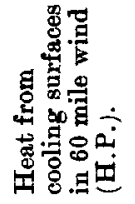 & 4 \\
\hline 1 & $\begin{array}{l}\text { R.A.F. 3A 12-Cyl. } \\
\text { Vee. Cyls. } 4 \frac{1}{2} \text { in. } \\
\text { by } 5 \frac{1}{2} \text { in. }\end{array}$ & $4 \cdot 7$ & $\begin{array}{l}1100 \\
1400 \\
1700\end{array}$ & $\begin{array}{l}155 \cdot 7 \\
190 \cdot 4 \\
214 \cdot 0\end{array}$ & $\begin{array}{l}0.520 \\
0.535 \\
0.548\end{array}$ & $\begin{array}{l}144 \cdot 0 \\
175 \cdot 0 \\
204 \cdot 3\end{array}$ & $\begin{array}{l}67 \cdot 0 \\
67 \cdot 5 \\
68 \cdot 0\end{array}$ & $\begin{array}{l}0.925 \\
0.915 \\
0.950\end{array}$ \\
\hline 2 & $\begin{array}{l}\text { Hispano Suisa. } \\
8 \text { Cyl. Vee. Cyls. } \\
4.72 \text { in. by } 5.11 \\
\text { in. (120 mm. by } \\
130 \mathrm{~mm} \text {.). }\end{array}$ & $4 \cdot 8$ & $\begin{array}{l}1000 \\
1200 \\
1400 \\
1600\end{array}$ & $\begin{array}{l}107 \\
130 \\
150 \\
168\end{array}$ & $\begin{array}{l}0.595 \\
0.587 \\
0.584 \\
0.580\end{array}$ & $\begin{array}{l}100 \\
115 \\
132 \\
143\end{array}$ & $\begin{array}{l}62 \\
62 \\
62 \\
62\end{array}$ & $\begin{array}{l}0.93 \\
0.89 \\
0.88 \\
0.85\end{array}$ \\
\hline
\end{tabular}


TABLE II.-continued.

\begin{tabular}{|c|c|c|c|c|c|c|c|c|}
\hline 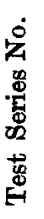 & Engine. & 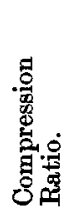 & 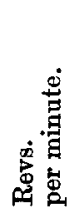 & 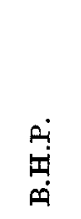 & 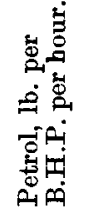 & 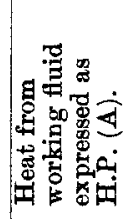 & 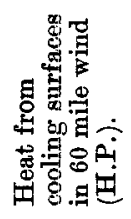 & 4 茟 \\
\hline 3 & $\begin{array}{l}\text { Fiat. } \\
\text { 6-Cyl. straight } \\
\text { line. Cyls. } 6 \cdot 3 \\
\text { in. by } 7 \cdot 08 \text { in. } \\
\text { (160 mm. by } 180 \\
\text { mm). }\end{array}$ & $5 \cdot 3$ & $\begin{array}{l}1000 \\
1250\end{array}$ & $\begin{array}{l}195.5 \\
244.0\end{array}$ & $\begin{array}{l}0.589 \\
0.579\end{array}$ & $\begin{array}{l}163 \\
195\end{array}$ & $\begin{array}{l}51 \\
51\end{array}$ & $\begin{array}{l}0.83 \\
0.80\end{array}$ \\
\hline 4 & $\begin{array}{l}\text { Renault. } \\
12 \cdot \text { Cyl. Vee. Cyls. } \\
4 \cdot 92 \text { in. by } 5 \cdot 90 \\
\text { in. (125 mm. by } \\
150 \mathrm{m.m} .) .\end{array}$ & $4 \cdot 8$ & 1200 & $224 \cdot 0$ & - & $216 \cdot 6$ & 169 & 0.97 \\
\hline 5 & $\begin{array}{l}\text { Sunbeam. } \\
\text { 12-Cyl. Vee. Cyls. } \\
3 \cdot 74 \text { in. by } 5 \cdot 32 \\
\text { in. (95 mm. by } \\
135 \mathrm{~mm} .) \text {. }\end{array}$ & $5 \cdot 2$ & 2100 & 223 & 0.520 & 199 & 55 & 0.89 \\
\hline 6 & $\begin{array}{l}\text { Mercedes. } \\
\text { Single-Cylinder. } \\
\text { Cyl. } 6 \cdot 3 \text { in. by } \\
7 \cdot 08 \text { in. }(160 \\
\text { mm. by } 180 \\
\text { mm.). }\end{array}$ & $\begin{array}{l}4 \cdot 5 \\
5 \cdot 0 \\
5 \cdot 5 \\
6 \cdot 0\end{array}$ & $\begin{array}{l}1400 \\
, " \\
, "\end{array}$ & $\begin{array}{l}26 \cdot 9 \\
27 \cdot 4 \\
28 \cdot 2 \\
28 \cdot 0\end{array}$ & $\begin{array}{l}0.551 \\
0.563 \\
0.565 \\
0.586\end{array}$ & $\begin{array}{l}23 \cdot 2 \\
22 \cdot 2 \\
22 \cdot 0 \\
20 \cdot 7\end{array}$ & $\begin{array}{l}\text { No wind } \\
\text { do. } \\
\text { do. } \\
\text { do. }\end{array}$ & $\begin{array}{l}0.86 \\
0.81 \\
0.78 \\
0.74\end{array}$ \\
\hline 6 & Do. & $\begin{array}{l}4 \cdot 5 \\
5 \cdot 0 \\
5 \cdot 5 \\
6 \cdot 0\end{array}$ & $\begin{array}{c}1600 \\
, " \\
, "\end{array}$ & $\begin{array}{l}30 \cdot 3 \\
30 \cdot 9 \\
31 \cdot 6 \\
31 \cdot 4\end{array}$ & $\begin{array}{l}0.593 \\
0.585 \\
0.593 \\
0.585\end{array}$ & $\begin{array}{l}25 \cdot 2 \\
24 \cdot 1 \\
23 \cdot 1 \\
21 \cdot 7\end{array}$ & $\begin{array}{l}\text { No wind } \\
\text { do. } \\
\text { do. } \\
\text { do. }\end{array}$ & $\begin{array}{l}0.83 \\
0.78 \\
0.73 \\
0.69\end{array}$ \\
\hline 7 & $\begin{array}{l}\text { Ricardo Tank Engine. } \\
6 \text { - Cyl. straight } \\
\text { line. Valves in } \\
\text { side pockets } \\
\text { with inlet over } \\
\text { exhaust. Cross- } \\
\text { head piston. } \\
\text { Cyls. } 5 \cdot 625 \text { in. } \\
\text { by } 7 \cdot 5 \text { in. }(143 \\
\text { mm. by } 190 \\
\text { mm.). }\end{array}$ & $4 \cdot 3$ & 1200 & $162 \cdot 9$ & 0.554 & $164 \cdot 2$ & $\begin{array}{c}\text { No wind } \\
- \\
- \\
- \\
- \\
-\end{array}$ & $1 \cdot 10$ \\
\hline 8 & $\begin{array}{l}\text { Adler "L" head } \\
\text { motor car engine. } \\
\text { 4.Cyls. Cyls. } 3.38 \\
\text { in. by } 5 \cdot 31 \text { in. } \\
(36 \mathrm{~mm} . \text { by } 135 \\
\text { mm.) }\end{array}$ & $4 \cdot 2$ & $\begin{array}{l}1200 \\
1400 \\
1600 \\
1800 \\
2000 \\
2200\end{array}$ & & $\begin{array}{l}0.620 \\
0.590 \\
0.571 \\
0.570 \\
0.580 \\
0.605\end{array}$ & & $\begin{array}{l}\text { No wind } \\
\text { du. } \\
\text { do. } \\
\text { do. } \\
\text { do. } \\
\text { do. }\end{array}$ & $\begin{array}{l}1 \cdot 58 \\
1 \cdot 51 \\
1 \cdot 46 \\
1.43 \\
1.45 \\
1 \cdot 51\end{array}$ \\
\hline
\end{tabular}


TABLE II.-continued.

\begin{tabular}{|c|c|c|c|c|c|c|c|c|}
\hline 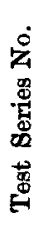 & Engine. & 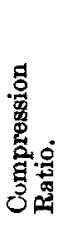 & 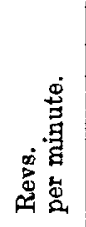 & $\underset{\sim}{\stackrel{\sim}{\infty}}$ & 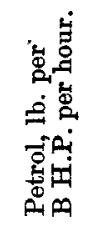 & 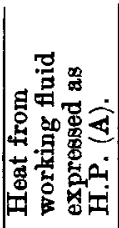 & 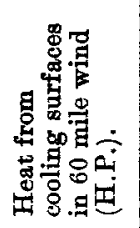 & $4 \mid$ \\
\hline 9 & $\begin{array}{l}\text { Air cooled single } \\
\text { aluminium cylinder } \\
\text { with ov erhead } \\
\text { valves. } \\
\text { Cyl. } 3.94 \mathrm{in} \text {. by } 5.51 \\
\text { in. (100 mm. by } \\
140 \mathrm{~mm} \text {.). }\end{array}$ & Air & $\begin{array}{l}\text { Cooled } \\
\\
1600 \\
1800 \\
1800 \\
2000 \\
2000\end{array}$ & $\begin{array}{c}\text { Cylind } \\
14 \cdot 6 \\
16 \cdot 2 \\
15 \cdot 1 \\
16 \cdot 1 \\
15 \cdot 3\end{array}$ & $\begin{array}{l}\text { ers. } \\
0.513 \\
0.543 \\
0.516 \\
0.534 \\
0.522\end{array}$ & $\begin{array}{l}15 \cdot 6 \\
18 \cdot 8 \\
16 \cdot 4 \\
17 \cdot 7 \\
16 \cdot 2\end{array}$ & 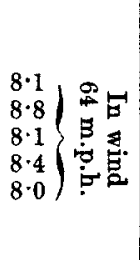 & $\begin{array}{l}1 \cdot 07 \\
1 \cdot 16 \\
1 \cdot 09 \\
1 \cdot 10 \\
1 \cdot 06\end{array}$ \\
\hline 10 & $\begin{array}{l}\text { Aiv cooled single } \\
\text { aluminium cylinder } \\
\text { with overhead } \\
\text { valves. } \\
\text { Cyl. } 4.5 \mathrm{in} \text {. by } 5 \frac{1}{2} \\
\text { in. (114 mm. by } \\
139.5 \mathrm{~mm} .) \text {. }\end{array}$ & $4 \cdot 6$ & $\begin{array}{l}1100 \\
1200 \\
1300 \\
1400\end{array}$ & $\begin{array}{l}13 \cdot 2 \\
14 \cdot 5 \\
15 \cdot 5 \\
16 \cdot 6\end{array}$ & $\begin{array}{l}0.560 \\
0.560 \\
0.552 \\
0.543\end{array}$ & $\begin{array}{l}14 \cdot 5 \\
15 \cdot 2 \\
17.4 \\
18.3\end{array}$ & 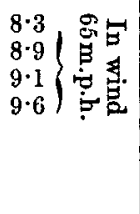 & $\begin{array}{l}1 \cdot 10 \\
1 \cdot 05 \\
1 \cdot 12 \\
1 \cdot 10\end{array}$ \\
\hline
\end{tabular}

(6) With the exception of Series 7 and 8, all these tests were carried out under the supervision of the author. The figures of Series 7 are given by the courtesy of $\mathrm{Mr}$. H. Ricardo from tests made by him. Those of Series 8 are from tests published by Prof. Riedler.*

Series 1 to 5 were carried out on standard aero engines, and the measurements were made in the course of full-throttle bench tests, with the petrol adjusted to give the weakest maximum load mixture for the particular engine.

The values of the heat-loss from the cooling surfaces, given in the penultimate line of Table II., have been computed in every. case for a mean jacket water temperature $65^{\circ} \mathrm{C}$. above that of the air.

Series 6 was carried out on a single-cylinder Mercedes engine in the course of tests to determine the effect of varying the compression ratio.

The tank engine of Series 7 is fitted with pistons of the crosshead type, and the air passing to the carburettors is circulated.

" "The Scientific Determination of the Merits of Automobiles." A. Riedler, The General Oil Publishing Co., Ltd., London. 
around the crosshead guides and under the pistons. During its passage the temperature of the air is raised about $60^{\circ} \mathrm{F}$. This degree of air cooling reduces the heat given to the walls. The value of A/B.H.P. deduced from the jacket water measurements alone is 1.01 . The absence of this air cooling would bring this value up to 1.05 , and an allowance of 5 per cent for radiation gives the value 1.10 given in Table II. It should be noted that with a crosshead piston the piston friction is reduced, and hence, to some extent, the heat given to the cylinder walls.

In the case of the air cooled cylinders of Series 9 and 10, a complete heat balance was abtained, the exhaust gases being passed through a calorimeter and an analysis being made from which the heat-loss due to unburnt petrol could be obtained. The heat-loss denoted in the last column of the Table is obtained by differences from the balance sheet; this includes the heat passing through the walls and piston and dissipated from the surface of the cylinder and crank case, and carried away by any oil vaporised in the crank case. The cylinder wall and fin temperatures were measured, and the same cylinders were afterwards erected as radiators in a wind tunnel with circulation of hot water through the barrel, and the actual heat dissipation from their surfaces at the same mean temperature and wind velocity as in the running tests was obtained. These values are given in the penultimate column of Table II. From these figures it appears that of the total heat dissipated from these cylinders, only 53 per cent in Series 9 and 60 per cent in Series 10 is actually removed from the cocling surfaces of the cylinder itself. The remainder, ranging from 49 per cent to 40 per cent of the heat equivalent to the brake horsepower is dissipated from the surfaces of the crank case and by oil vaporised from the lower surface of the piston and walls. These cylinders are lubricated by splash lubrication.

The author would draw special attention to these figures. The amount of heat dissipated from the internal surfaces of a petrol engine depends very greatly on the amount of oil reaching these surfaces. Where the oil supply is only sufficient to give adequate lubrication, this component of the heat dissipation is reduced; more heat must be removed from the outer cooling surfaces, and the cylinder temperature is increased. Variations in the degree of cylinder lubrication readily explain many of the inconsistencies which have been observed in temperature measurements on cylinders otherwise apparently similar. 
(7) General results of tests.-The results show that the heat transmitted from the working fuid to the cylinder walls and piston may range from 70 per cent to 150 per cent of the heat equivalent of the brake horse-power, depending on the design and conditions of operation of the engine.

(8) An examination of Series 1, 2, 3, 6, 8, 9 and 10 shows that under normal conditions of operation and for speeds below that giving maximum power, the speed of the engine has not a large effect on the heat transmitted per brake horse-power. Usually, as in Series 2, 3,6 and 8, this diminishes with an' increase. of speed. In Series 1, 9 and 10 the effect of speed is negligible. In general, the diminution in this ratio with increasing speed is more marked in an engine with eomparatively low compression ratio.

Table III. shows the temperature attained at a point on the side of the combustion space of an aluminium cylinder $4 \frac{1}{2}$ in. bore by $5 \frac{1}{2}$ in. stroke, with a compression ratio of $4 \cdot 7$, in a cooling wind of 53.5 miles per hour.

TABLE III.

\begin{tabular}{c|c|c}
\hline Revs. per minute. & B.H.P. & Temp. deg. C. \\
\hline 800 & $10 \cdot 2$ & 100 \\
1000 & $12 \cdot 8$ & 103 \\
1200 & $15 \cdot 4$ & 124 \\
1400 & $18 \cdot 0$ & 123 \\
1600 & $19 \cdot 7$ & 136 \\
1800 & 20.6 & 138
\end{tabular}

The temperature of the cooling wind was $22^{\circ} \mathrm{C}$. The tests were carried out at full throttle, with petrol and spark adjusted to give maximum load conditions at all speeds. The normal speed of the engine is 1,400 revs. per minute, and the result shows that from 1,200 to 1,800 revs. per minute the effect of speed on the cylinder temperature is very small. If the temperature-difference between the air and the cylinder at the given point be taken as a measure of the heat dissipated from the cooling surfaces, it appears that the heat dissipated per b.h.p. is 13 per cent less at 1,200 than at 800 revs. per minute, and 15 per cent less at 1,800 than at 1,200 revs. per minute. 
(9) From Series 6, it appears that the heat transmitted per b.h.p. diminishes appreciably with an increase in the compression ratio. Since, within limits, the brake horse-power increases with the compression ratio, the total heat to the walls does not diminish so rapidly as the ratio of A/B.H.P., and may, indeed, increase with an increase in the compression ratio. Tests on any given engine usually show that there is some fairly definite compression ratio giving a minimum wall temperature, and show that for moderate variations of compression ratio on either side of this value, the variation of temperature is small.

This point is brought out by the test figures from an aluminium air cooled cylinder of $100 \mathrm{~mm}$. bore by $140 \mathrm{~mm}$. stroke, under maximum load conditions in a 64 miles per hour wind, given in Table IV. Attention is drawn to the figures for petrol consumption and brake mean effective pressure in these tests, as indicating the possibilities of such a oylinder.

TABLE IV.

\begin{tabular}{|c|c|c|c|c|c|}
\hline \multirow{2}{*}{ 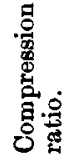 } & \multirow{2}{*}{$\begin{array}{c}\text { Brake } \\
\text { mean } \\
\text { effective } \\
\text { pressure. }\end{array}$} & \multirow{2}{*}{$\begin{array}{c}\text { Petrol, lb. } \\
\text { per } \\
\text { b.h.p. } \\
\text { per hour. }\end{array}$} & \multicolumn{2}{|c|}{$\begin{array}{l}\text { Mean temperature of } \\
\text { barrel deg. } \mathrm{C} .\end{array}$} & \multirow{2}{*}{ Remarks. } \\
\hline & & & Top. & Bottom. & \\
\hline $4 \cdot 6$ & $116 \cdot 2$ & 0.530 & 180 & 105 & \\
\hline $5 \cdot 0$ & $119 \cdot 3$ & 0.507 & 170 & 95 & \\
\hline $5 \cdot 4$ & $122 \cdot 0$ & $0 \cdot 490$ & 157 & 89 & \\
\hline $5 \cdot 8$ & $125 \cdot 0$ & 0.475 & 154 & 85 & \\
\hline $6 \cdot 2$ & $129 \cdot 0$ & $0 \cdot 480$ & 183 & 110 & Occasional pinking. \\
\hline $6 \cdot 4$ & $123 \cdot 0$ & 0.520 & 212 & 135 & Heavy pinking. \\
\hline
\end{tabular}

(10) Effect of cylinder dimensions. - The tests available are not sufficiently comprehensive to enable any decisive opinion to be expressed on the effect of a variation in the cylinder dimensions on the heat transmission per b.h.p. A comparison of the Fiat and Sunbeam engines (Nos. 3 and 5) which have sensibly the same compression ratio shows that the ratio A/B.H.P. is 10 per cent less in the Fiat engine which has a eylinder diameter 68 per cent greater. The comparison is, however, invalidated by the fact that the speed of the Sunbeam engine is 2,100 revs. per minute as compared with 1,250 revs. per minute of the Fiat. At the 
same speeds it appears probable that the ratio A/B.H.P. would bo about 20 per cent less in the large than in the small cylinder.

If a mean be taken of the values of A/B.H.P. from engines 1,2 and 4 , all of which have roughly the same cylinder diameter and compression ratio, and if this be compared with the value for engine 6 with the same speed and compression ratio, the result shows a mean diminution of 9 per cent in A / B.H.P. corresponding to an increase of 33 per cent in cylinder diameter. This question requires much further experimental investigation, but as a temporary working assumption based on these and other results, it may be taken that over the range of normal cylindior sizes each 10 per cent increase in cylinder diameter in engines of similar design diminishes the heat-loss to the walls per b.h.p. by about 3.5 per cent.

Since, however, in similar air cooled cylinders at the same speed of rotation, the horse-power is approximately proportional to the cube of the linear dimensions, the ratio of cooling area to heat given to the walls increases as the cylinder diameter is reduced. Taking into account the greater heat transmission per b.h.p. as the cylinder size is reduced, it may be taken as approximately true for similar cylinders and for moderate ranges of diameter that the temperature difference between an air cooled cylinder and the cooling air, in a given wind is inversely proportional to $\mathrm{D}^{0.6}$.

(11) Design.-The influence of design is shown by a comparison of engines 6 and 7 , of which the former has overhead valves, and the latter an L-shaped head. Making this approximate allowance. for the difference in cylinder diameter, the L-head cylinder transmits approximately 18 per cent more heat per b.h.p. to the walls than does the overhead valve cylinder. In this L-head cylinder the design is probably as clean as can be obtained with such a type of cylinder. In engine 8, also ah L-head engine of smaller size, the exposed combustion space area per unit of cylinder capacity is approximately 25 per cent greater than in engine 7 , while the ratio of A/B.H.P., when approximately corrected for differences in the cylinder sizes, is 20 per cent greater than in engine 7 .

(12) The strength of the working mixture has a very appreciable effect on the heat transmitted to the cylinder walls. The hottest cylinder is obtained with the weakest mixture aapable of main- 
taining maximum load. This is roughly a 13.5 to 1 air/petrol mixture. Any weakening of this mixture not only reduces the brake horse-power, but also the heat-loss per b.h.p., and so in a double degree tends to give a cooler cylinder. At the same time it gives an appreciably hotter exhaust, and so tends to cause overheating of the exhaust valves.

These points are well brought out by the figures in Table V. which are taken from tests on an air cooled aluminiuma cylinder $100 \mathrm{~mm}$. bore by $140 \mathrm{~mm}$. stroke (Engine No. 9).

\section{Table $V$.}

\begin{tabular}{|c|c|c|c|c|c|c|c|c|}
\hline \multirow[b]{2}{*}{ 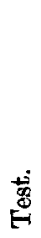 } & \multirow{2}{*}{ 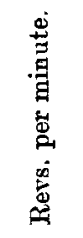 } & \multirow[b]{2}{*}{ 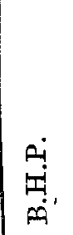 } & \multirow[b]{2}{*}{ 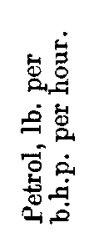 } & \multirow[b]{2}{*}{ 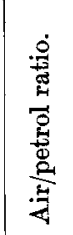 } & \multicolumn{4}{|c|}{ Heat balance expressed as H.P. } \\
\hline & & & & & $\begin{array}{l}\text { Unburnt } \\
\text { petrol. }\end{array}$ & B.H.P. & Exhaust. & $\begin{array}{l}\text { From } \\
\text { surface of } \\
\text { cylinder } \\
\text { and crank } \\
\text { case, etc. }\end{array}$ \\
\hline 1 & 1800 & $16 \cdot 2$ & 0.544 & $13 \cdot 6$ & 7.80 & $16 \cdot 2$ & $20 \cdot 3$ & $18 \cdot 3$ \\
\hline 2 & 1800 & $15 \cdot 1$ & $0 \cdot 516$ & $14 \cdot 9$ & $1 \cdot 64$ & $15 \cdot 1$ & $23 \cdot 3$ & $16 \cdot 0$ \\
\hline 3 & 2000 & $16 \cdot 1$ & 0.535 & $14 \cdot 0$ & $6 \cdot 07$ & $16 \cdot 1$ & $22 \cdot 0$ & $17 \cdot 2$ \\
\hline 4 & 2000 & $15 \cdot 3$ & 0.523 & $15 \cdot 0$ & $1 \cdot 00$ & $15 \cdot 3$ & $26 \cdot 1$ & $15 \cdot 8$ \\
\hline
\end{tabular}

Each pair of tests was run at full throttle under identical conditions except that the petrol supply in 1 and 3 was adjusted to the weakest maximum load mixture, while in 2 and 4 it was still further reduced so as to give approximately the maximum thermal efficiency on the brake horse-power.

TABLE VI.

\begin{tabular}{c|c|c|c}
\hline $\begin{array}{c}\text { Petrol, lb. per } \\
\text { b.h.p. per hour. }\end{array}$ & $\begin{array}{c}\text { Brake mean } \\
\text { effective pressure. }\end{array}$ & Air/petrol ratio. & $\begin{array}{c}\text { Exbaust valve } \\
\text { temperature deg. C. }\end{array}$ \\
\hline 0.622 & 122 & $11 \cdot 1$ & 706 \\
0.589 & 122 & 11.9 & 717 \\
0.515 & 119 & 13.8 & 747 \\
0.480 & 116 & 15.2 & 752 \\
0.470 & 114 & 15.7 & 747 \\
\hline
\end{tabular}


The figures of exhaust valve temperatures in Table VI. taken from tests on a similar cylinder, with a compression ratio of 5.5 , show that the maximum temperature is attained with an air/petrol ratio of about $15 \cdot 0: 1$ and a consumption of $0.490 \mathrm{lb}$. per b.h.p. per hour, whereas the maximum wall temperature is obtained with an air/petrol ratio of about 13.5:1.

A further increase in mixture strength beyond that necessary to give full power reduces the temperature of the cylinder surfaces. In this case combustion is very incomplete, the maximum temperature of combustion is diminished, while the evaporation of the unvaporised petrol entering the cylinder is a secondary reason for the reduction of the temperature obtained. This point is well shown by the figures in Table VII., which show the temperatures at the same point, near the centre of the head of an aluminium air cooled cylinder with overhead valves. The engine was operating at full throttle throughout at 1,400 revs. per minute. The only variable in the tests was the petrol supply to the carburettor. The air temperature was $23^{\circ} \mathrm{C}$.

TABLE VII.

\begin{tabular}{c|c|c|c|c} 
Test. & B.H.P. & $\begin{array}{c}\text { Petrol, lb. per } \\
\text { b.h.p. per hour. }\end{array}$ & Air/petrol ratio. & $\begin{array}{c}\text { Temperature of } \\
\text { cylinder head } \\
\text { deg. C. }\end{array}$ \\
\hline & 32.8 & 0.70 & 10.5 & 200 \\
1 & 33.2 & 0.64 & 11.4 & 215 \\
2 & 33.3 & 0.57 & 12.9 & 237 \\
3 & 32.9 & 0.54 & 13.5 & 229 \\
4 & 30.6 & 0.51 & 15.4 & 215 \\
\hline
\end{tabular}

(13) The timing of the ignition may have a pronounced effect on the maximum temperatures obtained, and on the heat dissipated to the walls, mainly because it largely governs the type of combustion. This effect is well shown by the figures in Table VIII., taken from tests on an aluminium-headed air cooled cylinder, $5 \frac{1}{2}$ in. bore by $6 \frac{1}{2}$ in. stroke. In these tests the only variable was the spark advance. The figure show the eylinder wall temperatures at the centre of the combustion head, in an 80 miles per hour cooling wind, at 1,450 revs. per minute.

s 2 
TABLE VIII.

\begin{tabular}{l|c|c|c|c}
\hline B.H.P. & $\begin{array}{c}\text { Petrol, lb. } \\
\text { per b.h.p. } \\
\text { per hour. }\end{array}$ & $\begin{array}{c}\text { Spark } \\
\text { advance, } \\
\text { degrees. }\end{array}$ & $\begin{array}{c}\text { Temperature } \\
\text { deg. C. }\end{array}$ & Remarkgs. \\
\hline 30.5 & 0.515 & 21 & 215 & \\
31.2 & 0.498 & 26 & 215 & \\
31.6 & 0.492 & 30 & 221 & \\
31.6 & 0.492 & 36 & 245 & Occasional pinking. \\
31.0 & 0.500 & 40 & 275 & Continuous heavy \\
pinking.
\end{tabular}

The figures show that so long as the spark advance is not so great as to produce pinking, it has comparatively little effect on the wall temperatures. Once pinking is set up, the temperature shows a very appreciable rise.

(14) Fuels.-The amount of heat transmitted to the cylinder walls varies somewhat with the composition of the fuel. The author has no evidence to show how it varies with the quality of the petrol, where this is used. A number of tests have, however, been made with petrol-benzol mixtures, with results that show that:-

(a) The heat transmitted to the walls per b.h.p. is somewhat less with a 20 per cent benzol mixture than with standard petrol.

(b) The difference increases with the compression ratio.

(c) The difference increases with the engine speed.

In the case of the single-cylinder Mercedes engine (No.6) the difference was:-

1.0 per cent with a compression ratio of 4.0

$2 \cdot 0$ per cent with a compression ratio of 5.0

3.0 per cent with a compression ratio of 6.0

at a speed of 1,400 revs. per minute.

As the power developed under normal conditions is about 5 per cent greater with a 20 per cent benzol mixture than with petrol, the total heat transmitted to the walls is sensibly the same whichever fuel is used.

This is borne out by the results of tests on an aluminium air cooled cylinder, tested with Shell A petrol and with a mixture 
of Shell $\mathrm{A}$ and 25 per cent benzol. In this case, the compression ratio was $5 \cdot 0$. At the same speeds the benzol mixture gave 5.3 per cent more power with a $2 \frac{1}{2}$ per cent increase in consumption by weight. The maximum cylinder temperatures were, nevertheless, sensibly identical, the difference being less than $5^{\circ} \mathrm{C}$. The difference is, however, very marked where, owing to insufficient cooling or a very high compression ratio, severe pinking or detonation is caused when working on petrol. The temperature of spontaneous ignition of a petrol-benzol mixture is appreciably higher than that of petrol, and under circumstances in which detonation is severe and overheating occurs with petrol, it is possible to obtain normal operation with normal temperatures if a benzol mixture is used.

(15) Working temperatures.-Experiment shows that the maximum temperature of the head of an air cooled cylinder should not exceed about $270^{\circ} \mathrm{C}$. for satisfactory working. With maximum temperatures of $200^{\circ}$ to $220^{\circ} \mathrm{C}$. results, both as regands petrol consumption and brake mean effective pressure, can be obtained which are quite as good as those from a water cooled engine of similar design and size. If the temperature exceeds about $280^{\circ} \mathrm{C}$., trouble is usually experienced through preignition, and plug trouble becomes apparent, but this is much more marked on some cylinders than others. Generally speaking, the larger the cylinder, the higher the permissible working temperature. The temperature of the exhaust valve at its hottest point should not exceed about $720^{\circ} \mathrm{C}$. In the case of valves not exceeding $1.5 \mathrm{in}$. in diameter, it is quite possible to keep down this temperature, under favourable conditions, to $650^{\circ} \mathrm{C}$.

In a well designed aluminium cylinder of the overhead valve type operating in a 60 miles per hour wind, experience shows that a provision of from 0.28 to $0.35 \mathrm{sq}$. ft. of cooling surface per b.h.p. is adequate to give the required temperatures under normal conditions of operation, the langer area applying to cylinders of about 4 in. bore, and the smaller to cylinders of about 6 in bore. For steel or cast iron cylinders with overhead valves, this area should be increased by about 30 per cent, and for L-head cast iron cylinders by 100 per cent.

Tests with reduced wind speds show that with a cylinder designed for a given air speed, the temperature increases and the power is diminished as the wind speed is reduced. Also the petrol consumption at maximum load is increased. Experiment shows that the difference of temperature between the hottest point of the cylinder head and the cooling air, under such circumstances, is 
approximately inversely proportional to $\mathrm{V}^{0.4}$. Thus in a given: series of tests, a reduction in wind speed from 80 miles per hour to 40 miles per hour increased the cylinder temperature from $229^{\circ} \mathrm{C}$. to $296^{\circ} \mathrm{C}$, the air temperature being $23^{\circ} \mathrm{C}$. The brake mean effective pressure dropped from $116 \mathrm{lb}$. per sq. in. to $106 \mathrm{lb}$. per sq. in., and the petrol consumption rose from 0.549 to $0.597 \mathrm{lb}$. per b.h.p. per hour.

Since the heat dissipation is proportional to the area of the cooling surface if this is equally efficient, and to the 0.73 power of the air velocity, the cooling area per horse-power for a given cylinder temperature should be inversely proportional to $V^{0.73}$. Thus a cylinder designed for a 60 miles per hour cooling blast will maintain the same temperature in a 30 mile wind, if the cooling surface be made $2^{0.73}(=1 \cdot 66)$ times as great.

There are, however, practical difficulties in the way of increasing the cooling area beyond a certain limit, and experience tends to show that a well designed aluminium air cooled cylinder of overhead valve type, and of 4 in. diameter, cannot be designed to give its maximum output on a really low potrol consumption in a wind of less velocity than about 50 miles per hour.

With smaller diameters the necessary wind velocity for the same wall temperatures, is less, the necessary velocity being approximately proportional to $\mathrm{D}^{\frac{0.6}{0 \cdot 73}}=\mathrm{D}^{0.82}$.

Table IX. shows then the minimum air velocity necessary for first class performance of air cooled cylinders of good design and material, under normal full throttle conditions.

TABLE IX.

\begin{tabular}{c|c}
\hline $\begin{array}{c}\text { Diameter, } \\
\text { in. }\end{array}$ & $\begin{array}{c}\text { Velocity, } \\
\text { miles per hour. }\end{array}$ \\
\hline & \\
2 & 30 \\
3 & 40 \\
4 & 50 \\
6 & 70 \\
8 & 90 \\
\hline
\end{tabular}

It is true that cylinders may be successfully operated on considerably lower air speeds, but only with reduced output and on appreciably higher petrol consumptions.

An interesting example may be quoted of an aluminium cylinder 
in which, after testing, alternate fins were first removed. The cylinder was re-tested, after which the whole of the fins were removed and the cylinder was again tested.i The diameter and stroke were $4 \frac{3}{4}$ in. by $5 \frac{1}{2}$ in. and the speed 1,800 revs. per minute. The results are given in Table $X$.

TABLE X.

\begin{tabular}{c|c|c|c|c}
\hline & $\begin{array}{c}\text { All fins } \\
\text { re- } \\
\text { moved. }\end{array}$ & $\begin{array}{c}\text { Alter- } \\
\text { nate } \\
\text { fins re- } \\
\text { moved. }\end{array}$ & $\begin{array}{c}\text { All fins } \\
\text { in. }\end{array}$ & \\
\hline \begin{tabular}{c|c|c|c} 
Cooling area sq. ft. \\
(including barrel)
\end{tabular} & 2.0 & 4.2 & 7.0 & \\
$\begin{array}{c}\text { Temperature of } \\
\text { cylinder head, } \\
\text { degrees C. }\end{array}$ & 360 & 270 & 220 & 70 miles per hour wind. \\
$\begin{array}{c}\text { Brake mean effec- } \\
\text { tive pressure. }\end{array}$ & 99 & 108 & 115 & 70 miles per hour wind. \\
$\begin{array}{c}\text { Petrol, lb.per b.h.p. } \\
\text { per hour. }\end{array}$ & 0.68 & 0.62 & 0.56 & 70 miles per hour wind. \\
\hline
\end{tabular}

For cast iron L-head cylinders the maximum air blast should be increased by at least 50 per cent.

(16) Temperatures at part load.-So far, the temperatures mentioned have all referred to continuous operation under full throttle. Under the normal operating conditions in automobile work this will seldom be necessary, and it is of interest to note how the working temperatures vary on the throttle. Table XI. shows the results of such tests on a $150 \mathrm{~h} . \mathrm{p}$. twelve-cylinder cast iron R.A.F.4A. air cooled engine at 1,600 revs. per minute.

TABLE XI.

\begin{tabular}{r|c|c}
\hline B.H.P. & $\begin{array}{c}\text { Petrol, ib. per } \\
\text { b.h.p. per hour. }\end{array}$ & $\begin{array}{c}\text { Cylinder head temperature, } \\
\text { degrees C. above air. }\end{array}$ \\
\hline 146.8 & 0.560 & 241 \\
123.8 & 0.555 & 221 \\
108.9 & 0.573 & 205 \\
89.0 & 0.585 & 174 \\
\hline
\end{tabular}


(17) Cylinder materials. - With cylinders of normal design, the middle portion of the head is the hottest point. The difficulty of keeping it satisfactorily cool is mainly due to the fact that the free air flow is impeded by the inlet and exhaust valve ports and valve gear, and that owing to the presence of these ports it is almost impossible to provide adequate cooling surface at this point. This results in the heat having to travel outwards, to be dissipated mainly from the cooling surface surrounding the combustion head., For a cylinder of given design, it follows that the best material to use, with a view to getting this heat away, is that of highest thermal conductivity. Of the three practical materials for cylinder construction, namely, steel, cast iron and aluminium, the latter has much the highest conductivity.

(18) Aluminium for cylinder work is used in the form of a copper-aluminium alloy. Table XII. gives a list of alloys which have been tested.

TABLE XII.

\begin{tabular}{|c|c|c|c|c|c|c|c|}
\hline \multirow[t]{2}{*}{ Drigignation. } & \multicolumn{7}{|c|}{ CoMrPosition. } \\
\hline & $\begin{array}{c}\text { CU. } \\
\text { per cent }\end{array}$ & $\begin{array}{c}\text { Sn. } \\
\text { per cent }\end{array}$ & $\underset{\text { per cent }}{\mathrm{M} g}$ & $\begin{array}{c}\mathrm{Zn} n \\
\text { per cent }\end{array}$ & $\begin{array}{c}\mathbf{A} l . \\
\text { per cent }\end{array}$ & $\begin{array}{c}\mathbf{N} i \\
\text { per cent }\end{array}$ & $\begin{array}{c}\mathbf{M} n \\
\text { per cent }\end{array}$ \\
\hline$B 4 \ldots \ldots$ & $7 \cdot 0$ & $1 \cdot 0$ & & $1 \cdot 0$ & $91 \cdot 0$ & $\cdots$ & $\cdots$ \\
\hline B $12 \ldots \ldots$ & $12 \cdot 0$ & $\ldots$ & $1 \cdot 5$ & .. & $86 \cdot 5$ & . & $\cdots$ \\
\hline B $17 \ldots \ldots$ & $14 \cdot 0$ & . & $\cdots$ & . & $85 \cdot 0$ & $\cdots$ & $1 \cdot 0$ \\
\hline B $18 \ldots \ldots$ & $8 \cdot 0$ & $1 \cdot 5$ & . & . & 89.5 & . & $1 \cdot 0$ \\
\hline B 19 & $8 \cdot 0$ & - & . & $\cdots$ & $91 \cdot 0$ & . & $1 \cdot 0$ \\
\hline B 25 & $9 \cdot 0$ & . & & $\ldots$ & $89 \cdot 0$ & $2 \cdot 0$ & $\cdots$ \\
\hline B 28 & $4 \cdot 0$ & . & $1 \cdot 5$ & .. & $92 \cdot 5$ & $2 \cdot 0$ & $\ldots$ \\
\hline L $8 \ldots \ldots \ldots$ & $12 \cdot 0$ & . & $\cdots$ & $\ldots$ & $88 \cdot 0$ & $\ldots$ & . \\
\hline $\mathrm{L} 11 \quad \ldots \ldots$ & $7 \cdot 0$ & $1 \cdot 0$ & . & . & $92 \cdot 0$ & . & $\cdots$ \\
\hline
\end{tabular}

The high zine alloys, which are suitable for crank cases and parts not subject to high pressures and temperatures, have also been tested, but are found to be most unsuitable for cylinder work, since their tensile strength is very low at temperatures exceeding $200^{\circ} \mathrm{C}$. The tensile strengths of typical sand castings from these alloys are shown in Table XIII. 
TABLE XIII.

\begin{tabular}{|c|c|c|}
\hline \multirow{2}{*}{ Alloy. } & \multicolumn{2}{|c|}{ Tons per sq. in. } \\
\hline & At 250 degrees $\mathrm{C}$. & At $3 \tilde{5} 0$ degrees $\mathrm{C}$. \\
\hline $\begin{array}{l}\mathrm{L} 11 \ldots \ldots \ldots \ldots \\
\mathrm{L} 8 \ldots \ldots \ldots \\
\text { B } 17 \ldots \ldots \ldots \ldots \\
\text { B } 28 \ldots \ldots \ldots \ldots \\
\text { B } 25 \ldots \ldots \ldots \ldots\end{array}$ & $\begin{array}{r}5 \cdot 5 \\
10 \cdot 5 \\
9 \cdot 5 \\
11 \cdot 0 \\
8 \cdot 5\end{array}$ & $\begin{array}{l}3 \cdot 0 \\
6 \cdot 0 \\
6 \cdot 5 \\
5 \cdot 0 \\
4 \cdot 5\end{array}$ \\
\hline
\end{tabular}

With the exception of the alloys containing manganese, all these alloys have approximately the same thermal conductivity (about 0.38 in C.G.S. units). The addition of 1.0 per cent manganese as in B.17 reduces the conductivity to about 0.27 , but this can be increased to a value approximately the same as that of the other alloys by annealing at about $450^{\circ} \mathrm{C}$. for a few hours. The relatively high conductivity of these alloys (0.38 as compared with about 0.12 for steel, or 0.10 for cast iron) combined with their low specific gravity (about 3.1 as compared with $7 \cdot 8$ for steel) renders them specially valuable for pistons and for the cylinder head castings of air cooled engines. The light weight enables a piston crown or a cylinder head to be made of comparatively generous thickness without being unduly heavy, and this, combined with the high conductivity, greatly facilitates the transference of heat from the hottest parts to the cooling surfaces.

All the aluminium alloys suffer from the drawback that they "grow" in volume on prolonged heating at the temperatures attained in operation. This "growth" is quite apart from distortion or thermal expansion, and in the case of a piston or cylinder head continues for the first 20 to 30 hours of operation, after which it apparently ceases. There is, as yet, insufficient evidence to show which alloys have the minimum "growth," though there is evidence that the presence of zinc as a constituent increases the "growth." In the case of a piston, the "growth" is not in itself sufficiently great to be practically important, and does not in general exceed 1 part in 1,000 on the diameter. Where "growth" and distortion takes place in the same direction the nett increase may, however, amount to as much as 1 in 250 . 
Experiment shows, however, that the "growth" in a piston or cylinder head may be forced by a preliminary period of annealing at a temperature of about $400^{\circ} \mathrm{C}$. for 5 hours, and as this also eliminates distortion, if it is carried out before the final machining, no further trouble is experienced in operation.

(19) Cylinder design and construction.-An air cooled cylinder with aluminium head is necessarily of composite construction, since the valve seats and the working surface of the cylinder barrel must be of some harder material than aluminium. Several types of composite construction have been tried with varying degrees of success. The valve seats may consist of rings of steel or of bronze, and these may be either cast or expanded into position. Both methods and both materials have been used with suceess. Owing: to the relatively higher coefficient of expansion of bronze, such seats are less likely to come loose under operating temperatures if expanded in than are steel seats.

One type of composite construction is shown in Fig. 1. Here the aluminium casting forms the head and surrounds the greater portion of the cylinder barrel. The latter consists of a steel liner which is shrunk into the casing at about $300^{\circ} \mathrm{C}$. The casingr itself is finned, and provides the barrel cooling surface., Several cylinders of this type, with diameters up to $4 \cdot 75$ in., have been tested and have given excellent results. On the other hand, the relatively high coefficient of expansion of the aluminium alloys $(0.000024$ as compared with 0.000012 for steel) tends to cause separation of the liner and casing at working temperatures, and this causes overheating of the liner and consequent drop in power and increase in petrol consumption. Some few cylinders have developed such trouble, which has always been traced to a badly fitting liner. This drawback becomes proportionately less important as the cylinder diameter is diminished, and for smaller diameters than 4 in. there is little reason to anticipate any diffculty of this kind. A shrinkage allowanee of about 1 in 600 on the diameter should be given.

The method of inserting the liner appears to be important, and better results are obtained when the cylinder is heated in hot air to the required temperature, than when heated in an oil bath. In the latter case the presence of the film of oil between casing and liner is probably responsible for a certain lack of thermal contact.

Tests on bronze liners have been made, and by this means. 
expansion troubles may readily be overcome. The wear of such a liner is, however, greater than that of a steel liner, though it is probable that investigation may enable a sufficiently hard liner of this type to be developed.

(20) Tests have also been made with screwed-in steel liners, but with unsatisfactory results. Such cylinders have always given

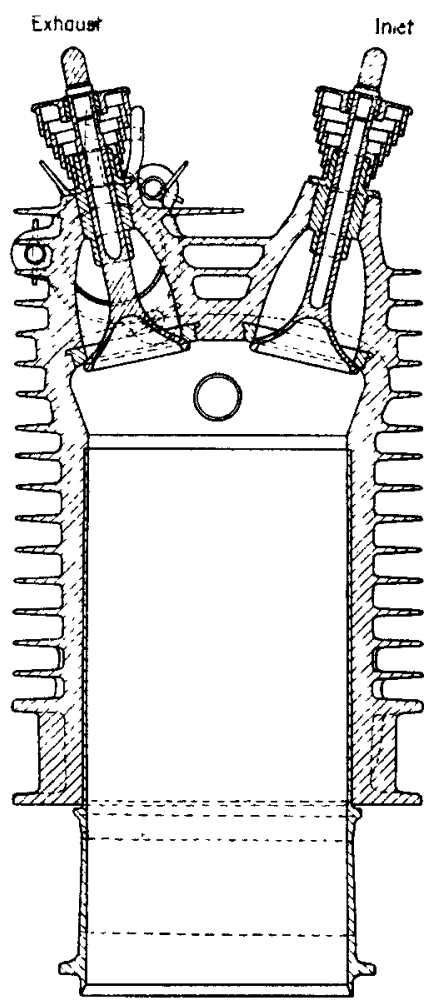

Fig. 1.

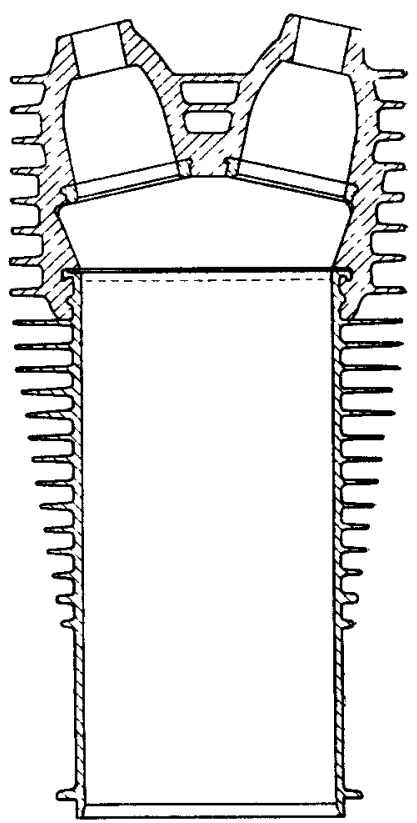

Fia. 2.

very high oil temperatures, indicating a hot liner, and on cutting the cylinder open after operation, lack of satisfactory contact between the liner and the casing has always been evident. The difficulty of obtaining good contact at all points of a long screwed liner is very great, and if satisfactory contact be obtained when cold, the difference of longitudinal expansion when hot causes the threads to touch only at isolated points. 
(21). In a third system of composite construction, the aluminium casting has been confined to the cylinder head, and into this has been cast or serewed the steel barrel with its own steel cooling fins as shown in Fig. 2. Mechanically this system has proved sound. The cast-in barrel has been used successfully in sizes up to 6 in. diameter, and the screwed-in barrel in sizes up to $5 \frac{1}{2}$ in. diameter. The holding down bolts now grip a ring, integral with the steel barrel. With a screwed-in barrel, the length of the screwed portion should be about one-fourth of the cylinder diameter.

(22) In another system, exemplified in a well-known. series of engines, the barrel and head are formed of steel in one piece. In aluminium cap embodying the inlet and exhaust ports is secured to the cylinder head by a series of bolts. This type is intermediate between the aluminium-headed cylinder and the all-steel cylinder.

(23) The author has had the opportunity of carrying out extended tests on the type of all-steel cylinder used in the Clerget, Lo Rhone, and other well-known aero engines. These tests have been on cylinder diameters ranging from 4 to 6 in. The tests show that for such sizes the all-steel cylinder gives very appneciably higher petrol consumptions than does the aluminium-headed cylinder, and that the brake mean effective pressure is lower. An interesting series of tests has been carried out by the author on a series of three cylinders differing only in the construation of the head. In one case this was of steel, with one aluminium inlet and two cast iron exhaust ports bolted to its outer surface., In the second (F'ig. 3), an aluminium cap was fitted to the head of the same cylinder; and in the third (Fig. 4), the original head was cut off and an aluminium head was cast on to the same barrel. The cylinder diameter was $5 \frac{1}{2}$ in. by $6 \frac{1}{2}$ in. stroke, and the compression ratio $4 \cdot 6$. The tests were carried out at 1,450 revs. per minute and in a wind of 82 miles per hour. The results showed that under maximum load conditions the aluminiumheaded cylinder gave 15 per cent more power than either the steel cylinder or that with an aluminium cap: The petrol consumption of the aluminium-headed cylinder was 26 per cent less than that of the steel cylinder and 20 per cent less than that of the capped cylinder.

It is true that the cylinder as originally designed was not very well adapted for the application of a cap, and probably appreciably 
better results could be obtained with this cap forming an integral part of the design. The author's experience, however, tends to show that unless such a cap is well bedded, the cylinder head is but little cooler than with the normal steel head, and that, however well fitted initially, "growth" and distortion of the aluminium cause lack of contact after some hours' running. Unless the cap be then rebedded the power falls off and the petrol consumption increases very appreciably.

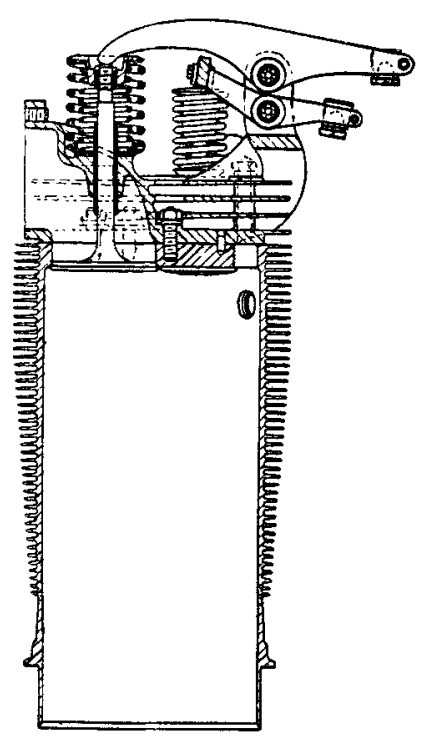

Fra. 3.

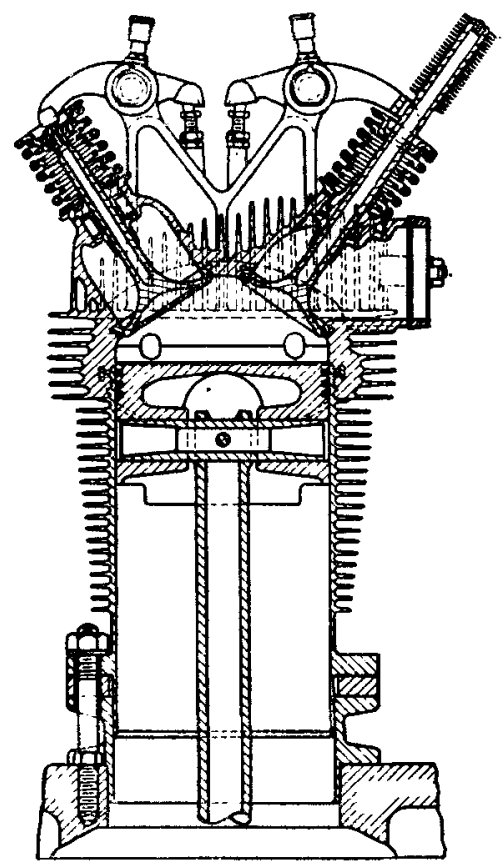

Fra. 4.

The largest all-steel cylinder so far tested by the author and his. colleagues has a bore of 6 in. and a stroke of 8 in. With a compression ratio of 4.48 and in a wind of 75 miles per hour this cylinder (Fig. 5) developed $115 \mathrm{lb}$. brake mean effective pressure on a petrol consumption of $0.68 \mathrm{lb}$. per b.h.p. per hour at 1,250 revs. per minute, and $105 \mathrm{lb}$. mean effective pressure on the same consumption at 1,600 revs. per minute. It had a single water cooled exhaust valve $2 \cdot 75$ in. diameter. Under similar conditions. 
an aluminium-headed cylinder of the same size developed $121 \mathrm{lb}$. brake mean effective pressure on a consumption of $0.56 \mathrm{lb}$. per b.h.p. per hour.

(24) Cylinders with longitudinal fins.-The large majority of the air cooled engines tested by the author have had circumferential fins surrounding the barrel and head, and have been

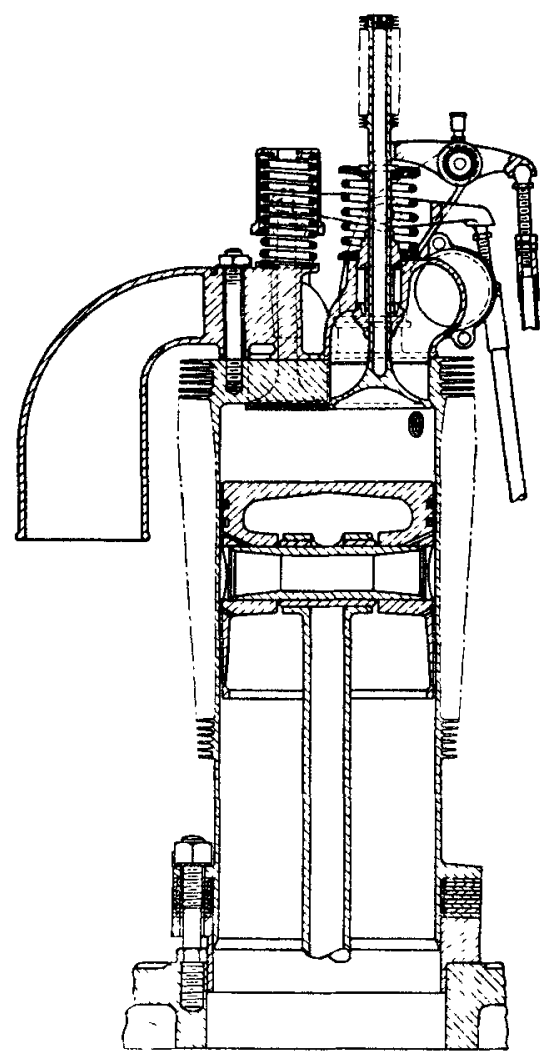

FIG. 5.

tested in a free air blast. Two, however, were of different design, with longitudinal fins down the barrel. One of these was a Franklin car engine, with six cylinders $3 \frac{5}{8}$ in. $(92 \mathrm{~mm}$.) bore by 4 in. stroke. Each cylinder carries a series of fifty-six parallel 
steel fins 0.064 in. thick, 0.785 in. deep and 8.0 in. long. Each cylinder is surrounded by a cowling closely fitting the fin tips
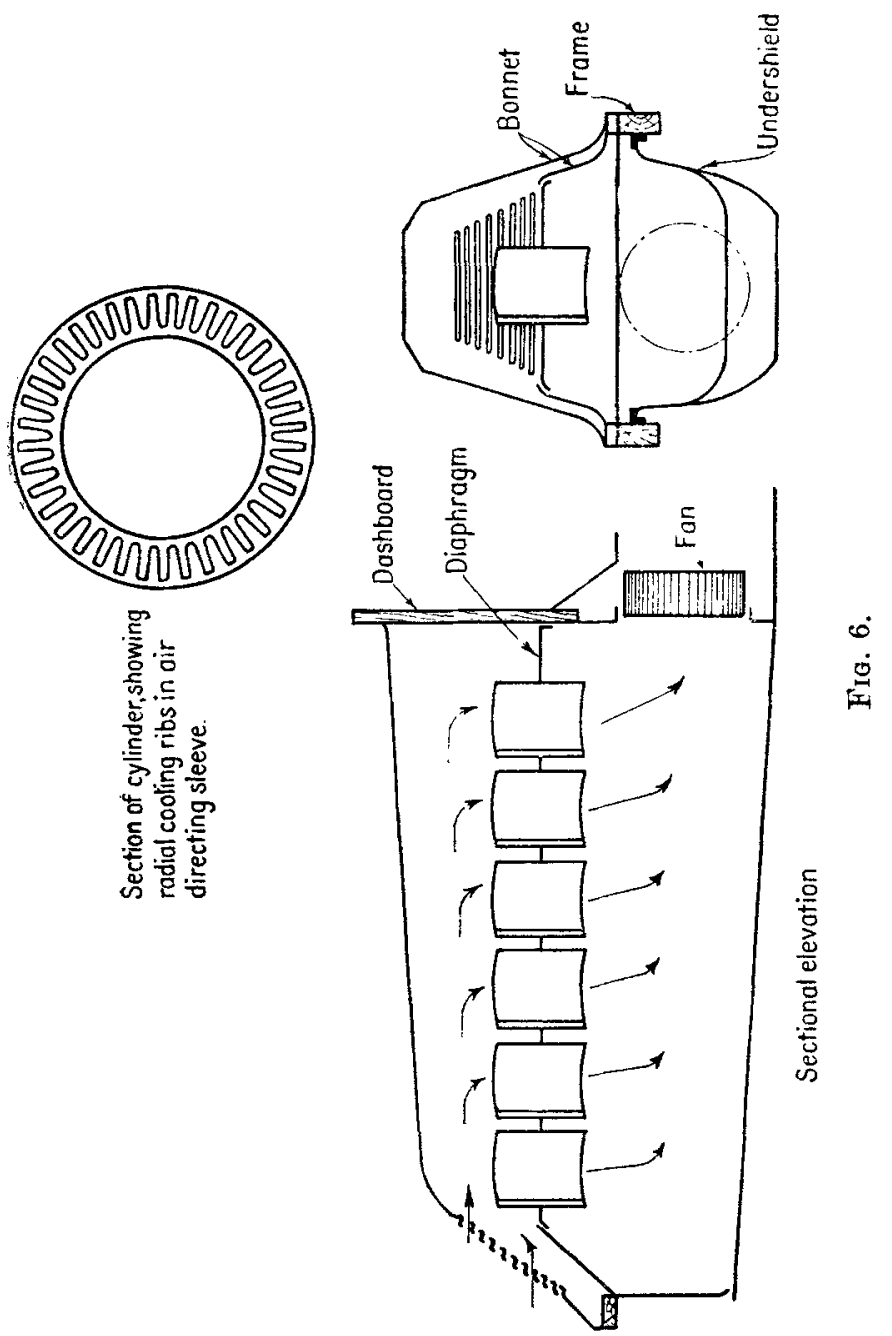

(Fig. 6), and air is drawn through these cowlings from top to bottom by a fan having a diameter of 20 in. and a width of 4 in. The mean air speed between the fins is 18 miles per hour with 
an engine speed of 1,200 revs. per minute, and 23 miles per hour with a speed of 1,600 revs. per minute. The engine has cast iron pistons. Owing to the very small clearance of the pistons in two of the cylinders, namely, 0.0020 in. and 0.0025 in., it was found impossible to run this particular engine at full throttle for more than ten minutes at a higher speed than 1,200 revs. per minute. At any higher speed the pistons in these two cylinders seized. At 1,200 revs. per minute the brake horse-power was 26.7 ; the brake mean effective pressure was $70 \mathrm{lb}$. per sq. in., and the maximum cylinder temperature $190^{\circ} \mathrm{C}$. Over a short run at 1,400 revs. per minute the engine developed $30^{\cdot 3}$ b.h.p., falling off to $24 \cdot 9$ b.h.p. in ten minutes, when the pistons seized. The maximum temperature half-way through this run was $251^{\circ} \mathrm{C}$., the wind speed being 20.5 miles per hour.

In the second cylinder of this type the bore was $110 \mathrm{~mm}$. and the stroke $140 \mathrm{~mm}$. This had a steel liner with an aluminium casing, carrying a series of 100 sheet aluminium fins 0.032 in. thick on the barrel, and thirty-four similar fins on the head. In. this case the cooling air was supplied under a pressure of $2.5 \mathrm{in}$. of water, and passed upwards between the fins with a mean velocity of 50 miles per hour. With a compression ratio of 5.2 , this. cylinder developed $116 \mathrm{lb}$. brake mean effective pressure on a consumption of $0.49 \mathrm{lb}$. per b.h.p. per hour at 1,800 revs. per minute, giving 21.4 b.h.p. The maximum cylinder head temperature was then $261^{\circ} \mathrm{C}$. This cylinder had a single inlet and a single exhaust valve, both overhead.

(25) Pistons. - Various types of piston have been used in the different tests. In many cases different pistons have been used in the same cylinder. The results all point to the general advisability of the aluminium alloy piston as compared with one of steel or cast iron. A series of temperatures taken on different pistons in a $100 \mathrm{~mm}$. by $140 \mathrm{~mm}$. aluminium air cooled cylinder, developing $115 \mathrm{lb}$. brake mean effective pressure at 1,800 revs. per minute, showed that the temperature of the crown of an aluminium piston of normal design, with a full skirt and with splash lubrication, was about $200^{\circ}$ to $250^{\circ} \mathrm{C}$, and was $200^{\circ} \mathrm{C}$. lower than that of the corresponding cast iron piston. The brake horse-power was 6 per cent greater with the aluminium piston, and the petrol consumption 5 per cent less. The weight of the cast iron piston was. 
$1.77 \mathrm{lb}$. and that of the aluminium piston $1.26 \mathrm{lb}$. The maximum olearances (cold) were 0.020 in. for the cast iron piston and 0.026 in. for the aluminium piston. The clearances hot were censibly the same, namely, about 0.008 in. These pistons are
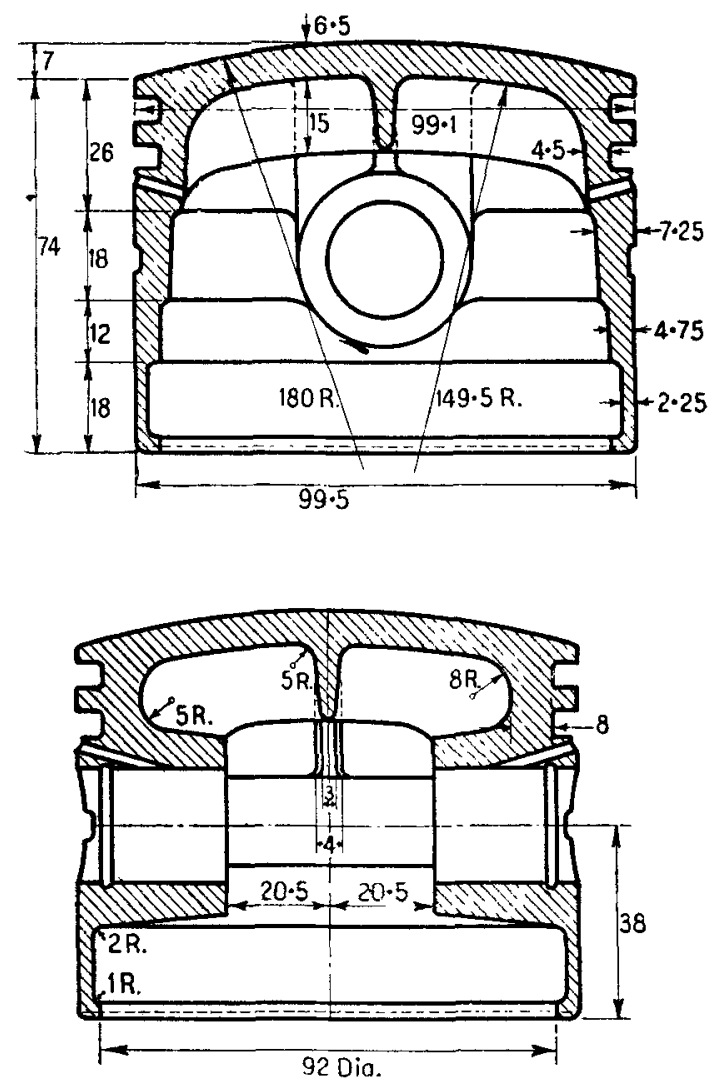

Fig. 7.

shown in Figs. 7 and 8. The cold clearance necessary over the top lands of an aluminium piston in a well designed air cooled cylinder is about 0.005 in. per inch of cylinder diameter.

(26) Cylinder distortion.-Other things being equal, cylinder distortion will be proportional to the difference of temperature GIBSON. 
between its hottest and coldest sides. Temperature distortion of the head itself is not usually serious, if the headitself is not of composite construction. One of the objections often raised against air cooling is that an air blast on one side of a cylinder leads to
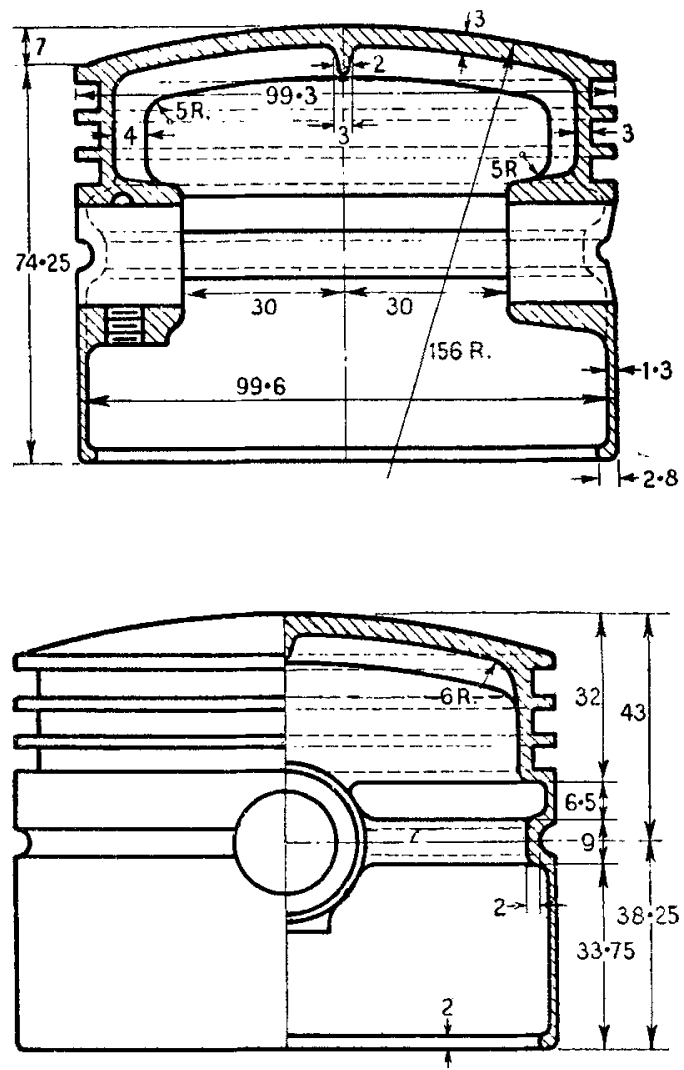

Fig. 8.

excessive distortion of the barrel. So far as the author's experience goes, this is not necessarily, or, indeed, generally, the case, at least with finned steel or cast iron barrels of reasonable thickness, or with finned aluminium casings fitted with steel or cast iron liners. 
In such cylinders the differences of temperature between the two sides of the barrel depend entirely on the way the blast is applied. The exhaust side is normally the hottest, and by applying the blast to this side, the difference of temperature between the two sides may become comparatively small. As an example, the following figures taken from tests on a $5 \frac{1}{2}$ in. air cooled aluminium eylinder may be of interest. With the blast on the exhaust side of the cylinder, the maximum difference of temperature between the front and back of the barrel was $58^{\circ} \mathrm{C}$., while the mean difference was only $19^{\circ} \mathrm{C}$. With the blast on the opposite, the inlet, side, the difference of temperature rose to a maximum of $180^{\circ} \mathrm{C}$. and a mean of $120^{\circ} \mathrm{C}$. In spite of this, however, the cylinder, which was fitted with an aluminium piston having only 0.025 in. clearance, showed no signs of binding after a prolonged run, showing that even in this extreme case and in a cylinder of this size, the distortion was not serious.

The results of a large number of tests on aluminium cylinders of $4 \mathrm{in}$. bore with the wind impinging on the side of the cylinder midway between the inlet and exhaust valves, show a mean difference of temperature of $56^{\circ} \mathrm{C}$. between front and back. Here, again, no evidence of distortion sufficient to have any practical effect has been noticed. A cast iron cylinder of the same design and wall thickness gave a mean difference, under the same conditions, of $63^{\circ} \mathrm{C}$., while an L-head cast iron cylinder of more normal design and wall thickness, also having the wind blowing across the cylinder, gave a maximum difference of $75^{\circ} \mathrm{C}$. and a mean difference of $68^{\circ} \mathrm{C}$. Here, again, the distortion had no apparent effect on the running of the engine. Since temperature differences are smaller with smaller diameters of cylinders, and since the effect of a given temperature difference is smaller as the cylinder barrel becomes stiffer, as will be the case normally in the smaller cylinders, there would appear to be little reason to fear the effects of distortion in any probable air cooled motor car engine.

While a cylinder with longitudinal fins has a comparatively even distribution of air flow around its periphery, this does not necessarily involve a lesser distortion. In the first place, with a cylinder of normal design the exhaust side is always the hottest, so that a cylinder with circumferential fins and a free air blast on its exhaust side will generally have a more uniform barrel s 2 
temperature than one with longitudinal fins. Furthermore, the stiffening effect of the circumferential fins, of which the outer portions are comparatively cool, is very appreciable, and with a given temperature difference across the barrel the distortion of such a cylinder is much less than that of the cylinder with longitudinal fins.

(27) Fan cooling.-With a fan of the propeller or centrifugal type, the volume of air moved with a free inlet and dischange is sensibly proportional to the speed of rotation. When installed so as to draw or force air through a cowling, the delivery becomes proportional to $\mathrm{N}^{x}$, where $\mathrm{N}$ is the number of revs. per minute, and $x$ is approximately 0.85 .

For a constant cylinder temperature, the wind speed. raised to the power 0.73 or $\left(\mathrm{N}^{0.85}\right)^{0.73}=\mathrm{N}^{0.62}$, should be proportional to the heat to be dissipated. Over the range of speeds throughout which the volumetrio efficiency is sensibly constant, and throughout which the brake horse-power and the heat to be dissipated are therefore proportional to the speed, the temperature of a fan cooled engine will increase with its speed of rotation.

Actually the brake mean effective pressure usually remains more or less constant up to about 0.66 of the speed giving maximum power, after which it falls off rapidly, with the result that the total heat to be dissipated at high speeds increases much less rapidly than the speed of the engine.

With a view of determining the effect of this, the author has obtained the values of the heat actually dissipated at different speeds up to the maximum load speed, for a series of engines. Taking the temperature difference between the air and the cylinder at this speed as unity, this difference has been calculated for lower speeds on the assumption that the engine is cooled by a fan of which the output varies as indicated above. The results are given in Table XIV. The data regarding the heat-loss from engines 1 to 4, are taken from tests by Riedler. Two of these engines are of the sleeve-valve type, and two of L-head type, both being motor car engines. The data for engines 5 and 6 , which are of the overheaid valve type, and of higher compression ratio, are from tests by the author. 
Table XIV.

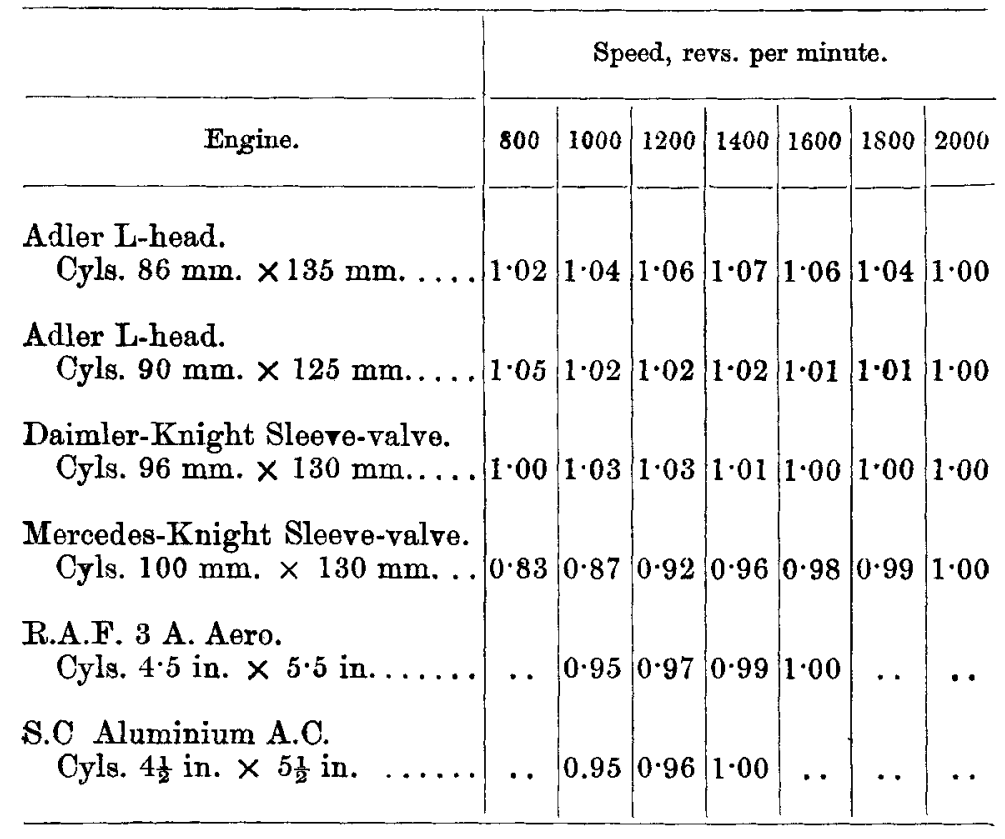

The figures show that the cylinder temperatures in these engines would only vary slightly with the speed over this range. In the first three, the maximum temperature would be attained at about 1,300 revs. per minute, and the engine would be actually cooler at higher speeds. In the last three, the maximum temperature would be attained at the highest speeds, but the speed effect is in no case very marked. It follows that the average car engine, if designed to cool when olimbing on low gear at maximum engine speed, will be adequately but not excessively cooled under all other conditions, except in so far as it is affected by the cooling wind due to the velocity of the car through the air.

Since the average car engine seldom works at full throttle for more than a few minutes on end, it is a matter for consideration as to whether it may not be possible to cut down the fan capacity so as to allow of temperatures somewhat higher than those desirable under normal conditions to be attained during the worst conditions, as for example when climbing a long hill on low gear with a following wind. Assuming an air temperature of 
$20^{\circ} \mathrm{C}$, it may be taken that with a well designed engine, the wind speeds given in paragraph is will enable a maximum cylinder temperature of approximately $240^{\circ} \mathrm{C}$. to be maintained. For short periods a maximum temperature of $280^{\circ} \mathrm{C}$. is permissible. The corresponding temperature-differences between the cylinder and the air are $220^{\circ}$ and $260^{\circ} \mathrm{C}$., the ratio being 1.18 . Since this temperature-difference is inversely proportional to $\mathrm{V}^{0.4}$, it follows that the wind speed may be reduced to $1 / 1 \cdot 18^{\frac{1}{0^{-4}}}=1 / 1 \cdot 18^{2.5}=$ $1 / 1.51=0.66$ of its normal value, without exceeding this higher limit of temperature-difference. The necessary wind speeds to be given by the fan at normal full engine speed in still air, should therefore be as in Table XV.:-

Table XV.

\begin{tabular}{c|c}
\hline $\begin{array}{c}\text { Cyl. diameter, } \\
\text { in. }\end{array}$ & $\begin{array}{c}\text { Wind speed, } \\
\text { miles per hour. }\end{array}$ \\
\hline 2 & 20 \\
3 & 25 \\
4 & 33 \\
\hline
\end{tabular}

It should be noted that these are the speeds necessary when the cylinders are of efficient type, well designed, and with adequate cylinder lubrication; when the engine itself is efficiently exposed to the cooling blast, i.e., when each cylinder is freely exposed; when the blast is directed on to the hottest or exhaust side of the cylinder, and when there is free egress for the heated air.

(28) Power absorbed in cooling.-Allowing a rise in temperature of $15^{\circ} \mathrm{C}$. for the cooling air during its passage over the engine, and assuming that $42 \mathrm{~B}$.Th.Us. are to be dissipated per minute from the engine surfaces per b.h.p. developed, this necessitates a volume, at atmospheric pressure and at, say, $15^{\circ} \mathrm{C}$., of $87 \mathrm{cu}$. ft. of air per minute per b.h.p.

At a velocity of 30 miles per hour ( $44 \mathrm{ft}$. per sec.) the theoretical horse-power required to produce this "cooling blast is only 0.006. The efficiency of these small fans, if well designed, is at least. 50 per cent or, allowing for frictional losses in the cowling, say 
40 per cent, so that the actual horse-power absorbed in cooling at full speed should not exceed 0.015 horse-power per engine b.h.p.

In an engine with L-head cylinders, the horse-power absorbed would be about 50 per cent greater than this, or 2.2 per cent of the engine horse-power, while if the wind speed were doubled, allowing the same rise in temperature, the horse-power absorbed would be quadrupled, since the horse-power of a fan is proportional to the produot of the weight of air and the squane of its speed.

Some measurements of this fan power were carried out on a 3i.A.F. 5, twelve-cylinder Vee fan cooled engine. Here the cylinders are of cast iron and of L-head design. The brake horse-power is 140 , the wind speed 60 miles per hour, and the fan, which is of the encased type, absorbs $9 \cdot 25$ horse-power at full speed, or 6.5 per cent of the engine power.

Tests by Riedler on the power absorbed by a cooling fan of the propeller type, used in connection with a water cooled stationary tractor engine, gave the following results:-

\begin{tabular}{l|r|r|r|r|r}
\hline Fan spe日d-revs. .......... & 710 & 900 & 1030 & 1140 & 1240 \\
Power absorbed (H.P.)...... & 0.10 & 0.20 & 0.30 & 0.40 & 0.50 \\
\hline
\end{tabular}

No figures are given as to the velocity of the cooling air, but at 1,240 revs. per minute, with a power consumption of $0.5 \mathrm{~h} . \mathrm{p}$., the heat dissipated from the radiator was the equivalent of $23.7 \mathrm{~h}$.p. The mean temperature of the radiator water was $75^{\circ} \mathrm{C}$. and the air temperature $16^{\circ} \mathrm{C}$. As the mean temperature-difference between the air and the cooling surfaces of the average air cooled cylinder is at least twice as great as in this radiator, even if the efficiency of the cylinder surfaces, owing to their form, is only 75 per cent as great as that of the average radiator (a figure lower than is indicated by experiment) this fan would dissipate the heat from an efficient air cooled engine of $22 \mathrm{~h} . \mathrm{p}$., absorbing 1.5 per cent of the engine horse-power in the prowess. 


\section{THE DISCUSSION.}

Mr. F. M. GreEN, in opening the discussion, said: I should like to impress on the meeting the great importance of the paper. When the author started his work, very little was known about air cooling, and the little that was known was entirely empirical, and I do not think it had ever been put on paper. The impression at the time was-and I am afraid that it still exists in many minds-that air cooled cylinders were necessarily worse in many respects than water cooled cylinders. In consequence of the author's work, I think it is fair to say that practically every objection to the air cooled cylinder has now been removed. As shown in the paper, the air cooled cylinder can give a mean effective pressure higher than that which is obtained in presentday motor cars, and very nearly as high as that which can be obtained from the best water cooled design. As far as reliability is concerned, air cooled cylinders have been run not for several minutes but for about four days continuously on full throttle. In one pre-war type mentioned in the paper the eylinder design was very poor in the light of modern practice, and I may say this without fear of offending the designer, as it was an engine for the design of which I was responsible, yet it was used a great deal in France, and it showed a higher average of time between overhauls than any water cooled engine with one exception. It used to run more than 100 hours between overhauls on the average, and it has frequently run for 200 hours without being taken out of the aeroplane.

Experience shows, too, that the petrol consumption of aeroplane air cooled engines is generally less than that usually obtained in modern car practice. Although the maximum results are not quite as good as the maximum results obtained with water cooling, they are within a very small percentage, and on the road there is reason to believe that the air cooled engine is likely to show to greater advantage, and I believe that the air cooled Franklin car gives a very good mileage. With regard to silence, not very much is known, but judging from the air cooled cars that have been built, there does not seem very much to fear. 
No doubt there are many hard headed practical motor engineers who will say that this is all very well for engines working in air speeds of 100 miles per hour, but that it would not do for motor cars which travel at much lower speeds. I agree that if we are to depend upon the speed of the car for the draught over the cylinders good results will not be obtained. Luckily, it is easy to use a fan for causing an air blast, and this fan need not take more horse-power than is usually absorbed in the cooling fan of the radiator of water cooled cars.

Again, I think I can imagine my hard headed friend saying it may be satisfactory in temperate countries, but not in the tropics. Contrary to general opinion, I think that air cooling has a big advantage in extremes of climate. In cold countries the advantages are obvious; in the tropics, the air temperature will only be about $20^{\circ} \mathrm{C}$. hotter than in England, and this will make the engine reach a temperature of $20^{\circ}$ above the figures shown in the paper. With a well designed cylinder this will do no possible harm, while if the temperature of a water cooled car exceeds $100^{\circ} \mathrm{C}$. the water will boil and cause trouble.

The cost of motoring, like everything else, is going up, and it is up to motor car designers to do their best to reduce it. The air cooled motor seems to me to offer the greatest chance of effecting: the saving. Air cooled engined cars will, I am sure, be lighter, cheaper and simpler to make, and air cooled cylinders can be designed to be much easier from the foundry point of view. I think, therefore, it will be to the national advantage if air cooling is developed in this country.

At the risk of treading on rather delicate ground, I would like to add one more remark. To my mind far too little notice is taken, and far too little use is made, of papers of the kind that we have heard to-night. The average practical man reads the paper and says, "it is all very well in theory," and lets it go at that. It is perfectly true that this paper is the work of a scientific man, but it is equally true that it is the work of a practical engineer of very wide experience. It has involved an expenditure of a great deal of work and a great deal of money. Both of these were provided by the nation, and $I$ ask automobile engineers very seriously to make a national use of the materials thus provided.

Mr. A. W. Reeves: It is interesting to note how very closely the author's facts come to the theory set out by Mr. Lanchester 
(Mr. A. W. Reeves.)

some years ago.* I have had a small amount of experience and a good deal of disappointment with air cooling, and I am. convinced that the system of air cooling for motor cars which depends upon the current of air produced by the passage of the car through the air is quite useless for anything but the smallest cars. In the system for which I am responsible, an induced. draught fan is used, and essentially it works on a system which Mr. Lanchester called the unit cell system, i.e., a system in which the air is split up into four columns, each of the columns of air traversing approximately one quarter of the circumference of the oylinder. The object of this, from my point of view, has not been so much to avoid distortion as to increase the volumetric efficiency of the fan. The air speed of the fan in my own engine is very, closely 22 miles per hour at 1,000 revs. per ninute, and the air current is taken over a cooling surface of 0.2 sq. ft. per b.h.p.; the cylinders are steel, and the horse-power obtained works out to a mean effective pressure of about 114 to $118 \mathrm{lb}$. per sq. in. On the same engine with an electric test the horse-power absorbed by the fan worked out to 0.6 at the maximum. I have worked very largely with the concentric type of valve, and that, in a cast iron head, showed the maximum temperature of the head immediately at the base of the valve seating to be $216^{\circ} \mathrm{C}$., and that compares favourably with the author's $280^{\circ}$.

Dr. Gibson: What was the horse-power?

Mr. Reeves: 25 h.p. when these figures were taken. One reason why I prefer the induced draught fan is that the car can be run practically all day on low gear and it will go up any incline that it has the power for and will never give any trouble from averheating. When the car is on low gear and doing about 8 miles per hour, the air speed approximates to 35 miles per hour, which is again near to the author's figures. My figures for petrol consumption in lb. per b.h.p. are a little unreliable, but taking the figures obtained on the road from last June until the present time, over a distance of about 15,000 miles, the consumption varied from 42 miles per gallon on petrol to 58 miles per gallon on benzol. The latter was recorded over a distance of 80 miles, and involved some big gradients. The maximum temperature of the air from the fan never exceeded $125^{\circ}$ to $130^{\circ} \mathrm{C}$. I think there is too much tendency to give all our attention to the external

* See Proc. I.A.E., Vol. X., p. 59. 
cooling of the engine, but the engine can be cooled internally by other means than by the excessive use of Iubricating oil. I have seen it stated that it is impossible to get an air cooled engine as. silent as a water cooled engine, but I am beginning to think that this is not so. Some people seem to imagine that the only noise an engine makes is due to the valve mechanism, but that is one of the easiest things to get over, and my experience has convinced me that an air cooled engine may be just as silent as a water cooled. engine. To obtain this silence, more attention should be given to the design of pistons, as the smaller the clearances the less the noise. In conclusion, I may say that I am absolutely of the opinion that we shall knock out the water cooled engine for motor cars in the next five or six years.

Mr. G. H. Lanchester: I feel sure that I express the views of all who have read this paper in saying that the author has given us a most valuable contribution towards making air cooling a commercial success. That air cooling for automobile engines will be an established success I have not the slightest doubt, but at present I am afraid it has got a good way to go before it becomes firmly established. With such scientists as the author and Dr. Fred Lanchester leading the way in the scientific development of air cooling, I feel I cannot contribute better to this discussion than by making a few observations on the practical difficulties, past and present, of air cooled engines, which will enable those who are working on the subject to avoid the mistakes which have been made in the past.

The majority of cars driven by air cooled engines are small and of moderate power, and where provision is made for forced draught, in general it is haphazard and rather inadequate. I am speaking of engines that have been on the market, because those are the ones that I have had an opportunity of judging. There are certain new ones at present, which have not been in the hands of the public long enough to demonstrate their capabilities and disabilities. So far as my knowledge goes there are no air cooled' cars of high power at present on the market, and only one car of medium horse power which ean claim any measure of sucoess. The early experimental air cooled cars designed by Lanchester had more efficient cooling organs than the 10 h.p. car marketed between 1900 and 1904, which had a considerable amount of trial in the public hands. This was due to three causes. First, 
(Mr. G. H. Lanchester.)

the cooling fins were of copper or aluminium in the experimental cars, but were of cast iron in the cars which were manufactured. Second, the fans directed cooling air into the cowling instead of sucking hot air from the jackets. Incidentally it may be said that the designers of the Franklin engine make the same mistake that we made; they arrange to suck hot air past the cylinders instead of driving cool air on to them. The third point was that in the 10 h.p. cars which we manufactured we rather choked the air discharge from the fans and considerably reduced their efficiency thereby. That was due to compliance with what was then regarded as the correct type of coach body. In the use of cooling fins of high conductivity we experienced a difficulty which to a large extent affected our decision to abandon shrunk on or detached fins and adopt the motor cycle practice of casting the fins integral with the cylinders, namely, that the copper or aluminium fins ultimately parted contact with the outside of the cylinder walls, the result of course being that the heat was not conducted to the air stream as it should have been. Oil got in between the cylinder walls and the cooling fins and formed a sort of carbonaceous insulation. This trouble may have been, and probably was, due to lack of knowledge as to the proper method of securing the fins to the cylinders, but our experience of the various methods employed during the war, of shrinking cylinder liners into aluminium jackets, showed that the trouble still exists; it is in this direction that one of the principal points of success in air conling lies. The designer who can find a way that is both thermally sound and commercially practicable will have gone a long way towards solving the problem.

The design of the cowling is a problem by no means easy of solution. As has been shown in the paper, directing air transversely across the cylinder is no disadvantage if the design is carefully considered, but it lends itself better to the Vee type or horizontal or radial engines than it does to the single-row vertical type. In the latter, it calls for an unsymmetrical arrangement, which is difficult to harmonise with the various surroundings of the cylinders, bonnet and coachwork. Taking the air draught vertically down the cylinders, Franklin fashion, gets over this trouble and also tends to cool the cylinder heads. It has, however, one rather grave disadvantage, that the hot air is blown 
direct on to the crankcase and tends to keep the lubricating oil at a high temperature, which makes for inefficient lubrication and consequent wear and tear of bearings. Reversing the direction of the cooling, taking it in at the base of the cylinder and out at the top, has the obvious disadvantage that it is difficult effectively to cool the cylinder heads.

In my opinion air cooling as applied to the automobile engine presents greater difficulties than in its application to the aero. engine, owing to two variables, i.e., the geographical character of the country, and the lack of skill of many drivers. I have. recollections of tests of all types of cars with which $I$ have been connected on a hill called the Snake, near Manchester. The geographical condition of the country there is such that the wind is nearly always blowing either up the hill or down it, and so. far as my experience goes, unless the car is sufficiently powerful to create a draught of 25 to 30 miles an hour in excess of the wind speed, there are few cars that will not overheat if travelling up the hill with a following wind. There are many similar hills. in this country, particularly in North Wales and Scotland, and there are no doubt many similar and worse hills in other countries. I know of no air cooled car that has ever come over the summit of the Snake when the wind is blowing up the hill without being overheated by the time it reaches the summit.

Mr. Granville ;Bradshaw: I think that Table IX., which shows. the minimum air velocity for first class performance of air cooled cylinders of different diameters, and Table X., which shows the increased petrol consumption with higher temperature, are at first glance apt to lead many to the opinion that air cooling is impracticable except under the conditions of a very extensive forced draught, whereas my own opinion is that this is not the case under any conditions that can be found in car service. Road tests that I have made with air cooled engines that have not been fitted with aluminium heads, and have had no forced draught for cooling, have completely failed to produce any signs that the engine is not functioning perfectly normally, and, in fact, the conditions have been such that many water cooled engines have shown signs of distress. It is of course perfectly true that the mean effective pressures obtained in the engines I referred to were not those obtained in the author's test, but from many years of experience, 
(Ar. Granville Bradshaw.)

on many makes of car, I am firmly convinced that with engines of the types in use to-day, a very high mean effective pressure is undesirable from the user's point of view, as it results in lack of smoothness when carbonisation takes place as well as a lack of capacity to maintain its tune. There can be no doubt that one of the most desirable points in a motor car is engine power at low speeds and its capacity for accelerating from about 10 or 12 miles per hour on top gear without having to change to low gear. Highly efficient valve gear and suitable induction systems do not produce these desirable conditions at low revolutions, and the designer of the air caoled engine is therefore compelled to consider the normal speed, power, and particularly the smoothness of the engine, on the test bench. This fortunately enables the production engineer - a very necessary and important individualto have his say in the commercial side of the design, and incidentally to avoid what I think most production engineers will be rather afraid of, the separate valve seats and sparking plug adaptors found in the highly efficient cylinders tested by the author. Personally I believe he has shown us what is perhaps the most efficient air cooled cylinder that has yet been designed, as far as its capacity on the test bench is concerned, but I feel also that whilst the information given is a most valuable guide in showing us what actually can be achieved in air cooling, the final results as they concern the motor car manufacturer are scarcely desirable. The Franklin engine suffers heavily by comparison in the author's test, and yet this car is very efficient under normal conditions of service in the average user's hands, and particularly in hot climates. A point we must not lose sight of, also, is that in all probability very few of the best and most desirable water cooled car engines to-day would show up well on comparative tests, and whilst I do not wish in the slightest to detract from the value of the paper, I am a trifle anxious lest a new designer contemplating the adoption of air cooling should imagine that the subject is a more difficult one than that of water cooling, and the recent increase of interest in the possibilities of air cooling be hampered in what should be its natural course:

Concerning cylinder distortion, the author refers to this only wherein it is affected by the air current, in which case it does not appear to be very great. My experience shows, however, that 
the principal distortion is that which is due to cylinder design and the position of the valve pockets. I believe that the majority of air cooled cylinders in use to-day are of cast iron with the exhaust valve pocket integral and situated on one side of the cylinder wall. In designs of this type I have measured a distortion to an extent of three times the normal piston clearance, and in one engine of a well known make, success was only achieved in use on Brooklands track by filing the piston on the tight side after each test until it was nearly 0.01 inch oval. The author's tests do not appear to include a cylinder of this type, and it is just possible that he may not have come across such distortion. If there is a real difficulty in designing a satisfactory air cooled engine for car work, my experience leads me to believe that noise from the valve gear is the most prominent one. The water jackets round a cylinder seem effectively to take away all clatter and change it to a dull note, and this difficulty is increased in an air cooled engine by the higher expansion in such an engine which increases the clearance between the valves and the valve tappets. The latter can be minimised, if not actually removed, by the use of an overhead camshaft carried on the cylinder head, but this limits the arrangement of the cylinder on the crankcase very considerably, and clearly calls for a "lineahead" arrangement coupled with a camshaft which renders the cylinder and head inaccessible. Unfortunately the author's tests appear to preclude the alternative of a sleeve or sleeves for the valves in an air cooled engine, as these may be judged almost entinely in their effect as liners similar to that shown in Fig. 1, which gave trouble through overheating when the liner separated from the cylinder barrel.

Concerning petrol consumption, I feel that from the car designer's point of view full-throttle tests on the bench are nothing very much to go by, the real test being that on average roads at average speeds, and this re-assures us concerning Table $\mathrm{X}$, wherein we see the effect of very high temperatures on the petrol aonsumption. It would be interesting to see the other end of this curve and to find the effect of too low a temperature on the consumption, such as when travelling at, say, 15 miles per hour and employing a very efficient fan. The data that the author presents to us are extremely useful at this stage of the develop- 
(Mr. Granville Bradshaw.)

ment of air cooled cars if we study them carefully and do not aim at too high an efficiency. In this case the paper gives us the greatest hopes of success, as the power he has obtained and maintained is of the highest order, the petrol consumption is comparable with the best of water cooled engines, and the compression ratios are considerably higher than would be desirable on the road, in which item alone we have a great factor of safety.

Col. W. A. Bristow: The effect of the timing of the ignition on wall temperatures which has been dealt with in the paper raises an interesting question. In the experimental results the variation of the timing is given as from 25 to 40 degrees, and it is rather curious that there should be so little difference in horsepower over that range. Apparently from the figures, the engine was best when running with an advanoe of 30 degrees, and the minimum advance given was 21 degrees, so that the only figures we are interested in are the results between these two points. These are insufficient to enable us to determine what the effect of retarding the ignition would be when applying these engines to a car, because angles of retard of probably three times that dimension would have to be dealt with, and people are so very careless that they frequently forget to put forward the ignition after retarding it. If a retanded ignition will have an effect upon the exhaust valve temperature, it would be interesting to get figures showing what increased air velocity would then be necessary for proper cooling. If the results of experiments show that the temperature will go up considerably, it may have an effect on the air velocity that would be considered necessary. Figures with regard to velocity would sem to show that for most small cars a velocity of about 40 to 50 miles per hour would be required, although the author qualifies that later in the paper, by taking into consideration the car air speed that might be expected, and striking a lower average.

A point in the paper which is rather opposed to recent experience. is the statement that the rise of temperature of the air was $15^{\circ}$. From recent measurements I should think it would be considerably less, and that the amount of air to be passed would be very much increased. Experience in other work would seem to show that the power required by the fan is as much as four times that indicated in the paper. It was also noticed in some of these experiments that the velocity across the different parts of the slip stream varied enormously according to the action of the 
fan and the arrangement of the engine in the cowling, and also the neighbouring projections, and measurements taken showed a difference of velocity of 1 to 3 in different parts of the slip stream. If a minimum velocity point happened to coincide with a hot point in the engine, it might lead to serious trouble. There is, $I$ think, some useful work to be done in investigating the cross sectional velocities at different points. With regard to the point raised by the author that most engines in this country are not subject to maximum throttle for long, I would rather think that on the whole many engines are subject to full throttle for quite long periods. But even if the engines are not under full throttle, at full speed they may be under conditions which are even worse than full throttle, and having the very best wishes for air cooled cars, in the future I hope people will not attempt to cool them at velocities below the figures given in the Table. I thoroughly agree with Major Green as to the value of the work done by the author, and I only hope that designers in this country will be quick to take advantage of what has been done, and thus secure a premier position in what promises to be a very useful branch of engineering.

Mr. A. Roy FEDDEN: I have no doubt that there is going to be a great development in air cooling for all types of internal combustion engines, and I would venture to say that this paper may almost be said to be in the category of a classic. It is the first paper I have ever seen that has given the design side any real data to work upon, and I think it is a most valuable one. It seems to me that in considering this paper we must divide it into two, and discuss it from the point of view of aero engines and of motor car engines. I am quite sure that motor car engines at present cannot and must not develop brake mean effective pressures that are actually proven for aero engines, and that petrol consumptions and performances generally must be lower.

I am not quite clear about the statement on page 243, that " For a given material the heat dissipation is sensibly independent of the roughness of the surface." From my own experience I have found a definite improvement with a smooth surface, and with the enamels which the author gave me in 1917 , there was a distinct lowering of the temperature of $10^{\circ}$ to $15^{\circ}$.

Dr. Gibson: You said smoothness. Do you mean that a smooth metal surface has, in your experience, given a better result than a rough metal surface?

GIBSON. 
(Mr. A. Roy Fedden.)

Mr. FeDDEN: Yes, and steel treated with a phosphoric acid or the "Coslet" process definitely gave a decrease in temperature of 6 to 7 per cent.

With reference to the author's experiments on pitch, I take it that he refers to the mean of the space between two adjacent fins. I have found a steel cylinder $4 \frac{3}{4}$ in. bore and with fins $\frac{1}{4}$ in. pitch, measured as per the author's formula, give very satisfactory resuits. Table VI., I consider, is a most interesting and instructive one, but some figures in connection with my own experiences show slightly higher temperatures as regards exhaust valves. I have found that the exhaust valve of an air cooled cylinder of $5 \frac{3}{4} \mathrm{in}$. bore and $7 \frac{1}{2}$ in. stroke, with a petrol consumption of $0.54 \mathrm{lb}$. per b.h.p. per hour, a mean effective pressure of $116 \mathrm{lb}$. per sq. in, and an air/petrol ratio of 14, running for some hours in a wind speed of 70 miles per hour, reached a temperature of $760^{\circ}$; with that temperature the cylinder is capable of running for long periods. 1 would submit that the $0.28 \mathrm{sq}$. ft. area which the author stated was permissible in design, is almost prohibitive for large cylinders on aero engines owing to the difficulty of getting the necessary area and also on account of the weight, and I submit that the figure of 0.21 to $0.25 \mathrm{sq}$. ft. per b.h.p. is nearer the possible limit, for such big cylinder bores as 6 in. I would also suggest that it is advisable to divide this into two, because it is obvious that the cylinder head is the crucial point and that a very much bigger surface is necessary per b.h.p. there than on the barrel.

In connection with aluminium alloys and the casting of complicated cylinder heads, I have found that 2.L.11 has a distinct advantage from the foundry point of view. In reviewing the author's remarks on cylinder design, I would like to say that I am very keen on having all parts so that they can be easily viewed, and although $I$ know the wonderful results that have been attained with R.A.E. cylinders, I think their success in a great measure is due to the excellent foundry organisation. I would put forward a claim for the poultice head type of cylinder because that can be easily viewed; and I believe that provided it is possiblie to set out with that design in mind from the beginning; the very. important point that the author raises as to the proper cooling of the head can be obtained. I have run tests for 100 hours in a 55 miles per hour wind and the conductivity was absolutely; definite. It might be of interest to give some information in connoction with attempts to design an air cooled engine for a motor 
aar since the war, and whilst most of the problems have already been met in connection with aero engines, 1 must say that it is not such an easy matter as some people seem to think. I first join issue with Mr. Lanchester on the question of not keeping cool. I wish Mr. Lanchester would try one of our air cooled cars over such hills as Porlock and Beggar's Roost where maximum' power is required to get up at all. I agree with Mr. Bradshaw on the question of noise. The air cooled engine makes a tinkling noise, which is very difficult to get over, and which is quite distinct from that of the closing of the valve on its seating. Water cooled engines have a definite help in that respect, in that they have a bigger mass of metal in the head and the water itself helps to deaden the noise. In the particular engine in which I am interested, which is a three-cylinder air cooled radial of $80 \mathrm{~mm}$. bore, $75 \mathrm{~mm}$. stroke, the cooling is by a positively driven fan in front of the engine which directs cool air on to the cylinders, and the figures which the author has given and thoise which we have obtained are very near together. I find that at 2,000 revs. per minute we are getting a slip stream 'on the cylinder heads of 40 miles per hour, but our fan absorbs more power than is stated in the paper. The actual horse-power absorbed at 2,000 revs. per minute is about 0.95 , and we are not aiming at an abnormal mean effective pressure. I have gone to a slightly greater figure in the cooling surface than is quoted in the paper, the actual figure being $0.645 \mathrm{sq}$. ft. per b.h.p. As regards petrol consumption, I agree with Mr. Lanchester's view that what we want to get is the ton-mileage, and up to the present, when driven hard at a high average speed, I think we can rely on 36 to 38 ton-miles. As regards the performance of the air cooled engine on the test bed, there is no difficulty in keeping the engine cool. We know that there are a good many pre-war motor car water cooled engines that have got very sick and sorry when they have been run on full throttle for about 40 minutes, and I feel quite sure that with the data that we have now got, for small engines up to 2,000 c.c., the problem of air cooling is not a great one, although I do say that there are many other problems.

Mr. A. A. Remrigaton: I think, in the first place, that we are rather making a mistake in trying to create such a big gulf between the air conled and the water oooled engine for motor car work. After all, the heat has in all cases got to be dissipated' from the cylinder wall to the air, and it is only in the intermediate 
(Mr. A. A. Remington.)

means for doing so that the difference lies. The air cooled cylinder is directly air cooled, so that the heat has only to traverse the cylinder walls, whereas the water cooled engine has the water as well as the metal interposed between the cylinders and the atmosphere. The principal difference between the two systems is that with water we can take advantage of the car speed through the air to provide the principal draught to effect the cooling, because we can have such a much larger surface exposed to the air than is possible in direct air conling, and so can get adequate conling with a lower air speed than is possible with water. Again, water is not without other advantages. There are very few cars indeed that can olimb hills indefinitely all day on the low gear without overheating, which, in water cooled carrs, means boiling the water, and it is usual ta proportion things so that though the temperature rises upon climbing, the water will not boil on the longest hill the car is likely to encounter. The "mass:" of the water in that way is valuable, as it forms a sort of heat flywheel which stores heat when elimbing and dissipates it when the circumstances are more propitious. That valuable feature is sacrificed to a very great extent in the case of direct air cooling, and it becomes necessary to make the air cooled motor car engine capable of disposing of its heat as fast as it is created under all conditions. From what I have heard in the discussion, I gather that it is necessary in air cooled motor car engines to have such a fan capacity that the heat can be dissipated at full throttle under all conditions, and I gather that this is one of the difficulties, although one speaker assured us that keeping the engine cool is no difficulty at all, but that the difficulty lay rather in keeping" it at a sufficiently uniform temperature under varying loads and conditions. Mr. Lanchester raised a number of difficulties in connection with the Lanchester air cooled car of 1900 which, if I recollect aright, was contemporary with water cooled cars that had peculiarly inefficient radiators and cooling systems and habitually boiled their water away to get rid of the surplus heat, and I am sure that if Mr. Lanchester again tackled the air cooling: problem, he could give us an air cooled car that would perform in relation to his old most interesting product as well as does the water cooled car of to-day in relation to the water cooled car of twenty years ago. In regard to the power required for driving the fan for direct air caoling, I can confirm the figures given by the author. An air cooled aero engine made during the war 
by the firm with which I am associated, gave $100 \mathrm{~h} . \mathrm{p}$. on the brake with the fan in action, but when the fan wlas removed and the cooling supplied by an extraneous draught, the power went up to $106 \mathrm{~h}$.p., showing that the power absorbed by the cooling fan was almost exactly 6 per cent.

I must join issue with Mr. Lanchester with regard to the "ton-miles" basis for comparison. I do not think it is reasonable to compare cars of the same carrying capacity but of essentially. different tare weights, such as the case of water cooled and air cooled cars, on the basis of ton-miles per gallon of fuel consumed. The air cooled car with only a fan to supply the cooling is essentially lighter than the water cooled car, and thenefore on equal fuel efficiencies the ton-miles per gallon obtained from an air cooled car should be higher than those obtained with a water cooled engine. I do not know what value the allowance should have, but it could easily be worked out, and the air cooled car on considerations of fairness should be credited with that amount., Before I close, I will say that I have never had any experience of air cooled cars, and while I hold the opinion that air cooling for low powered motor cars may come into general use fairly soon, it seems to me that the general aair cooling of motor cars. and the consequent superseding of water cooling for internal combustion engines used for transport is yet a very long way off, although in these days of rapid development it is very unsafe to even suggest what may or may not come about in future, even in the very near future.

Captain J. S. InviNG: I should like to congraitulate the author on having condensed the results of about four years' work into: a paper of 35 pages. He has concentrated on this question for something over three years at the R.A.E., and I know that his results are given after many careful experiments, and that he can repeat these results at any time, which is not always the case when delicate experimental work is under consideration.

This paper should be divided into two parts for discussion purposes; first, the air cooling of petrol engines, and, secondly, the application of air cooled engines to motor cars. In connection with the first part, I should like to query some of the figures. In Table II., referring particularly to the petrol consumptions, some of the best known engines in Europe are dealt with, and the petrol consumptions are consistently high, the lowest and best consumptions being given by air cooled engines. We can hardly, 
(Captain J. S. Irving.)

claim to obtain better results with air cooled engines, and if the consumptions of the water cooled engines are corrected to what is usually obtained, the results may be slightly different. On the author's statement that practically 50 per cent of the heat loss is dissipated through the pistons and the crankcase walls, the use of aluminium pistons would have a very appreciable effect on the cylinder temperature of any engine, particularly an air cooled engine. This effect was noted on the R. A. F. 1A engine with cast iron cylinders when the cast iron pistons were replaced by aluminium pistons. The author does not make any reference to the effect of copper depositing. We have heard very varied opinions as to the effects to be obtained from this process, and knowing that the author has carried out a long series of experiments on this point, I hope he will summarise a few of the results for us. With regard to the question of the loose aluminium head, in the particlular cylinder that was first tested by the author, remarkable results were obtained in the first few hours' running, and for somethingover 30 hours those results were maintainod, after which there was a gradual falling off in power until the aluminium eylinder head was removed after 50 hours' running and was found to have lost contact with the steel cylinder barrel. The head was carefully refitted and the tests were continued, and the same deterioration occurred again after, I believe, 35 hours' running. It was again refitted, and the power then fell off after 28 hours' running. If that was so, it seems to show that the preliminary annealing of the head casting before being fitted to the cylinder will not get over that trouble. The author has given some figures of the Franklin car, and I have made a rough estimate of the cooling. surface available. The fins give $4.9 \mathrm{sq}$. ft., the barrel $1.3 \mathrm{sq}$. ft., and the head $0.5 \mathrm{sq}$. ft., making a total of $6.7 \mathrm{sq}$. ft., equivalenit to one and a third square feet per horse-power. That engine developed 30 h.p. with six cylinders, and that would give a brake mean effective pressure of approximately $67 \mathrm{lb}$. per $\mathrm{sq}$. inch, so that it would seem that that engine is overcooled. I am of the opinion that the air cooled engine will be seriously applied to. light motor car work. We shall probably find difficulties, but we also had difficulties with water cooling, and they will be overcome.

The average water cooled engine in a high class touring car rarely exceeds $90 \mathrm{lb}$. per sq. in. brake mean effective pressure, 
and this point considerably simplifies the application of air cooled engines to motor cars, as the cooling surface will be considerably less than that necessary on the air cooled engines dealt with by the author with brake mean effective pressures in the region of $130 \mathrm{lb}$. per sq. in. The petrol consumption on the car engines is also usually $0.7 \mathrm{lb}$. per h.p. per hour. If we consider a fourcylinder engine $80 \mathrm{~mm}$. by $150 \mathrm{~mm}$., with $90 \mathrm{lb}$. per sq. in. brake mean effective pressure, and an average consumption of $0.7 \mathrm{lb}$. per b.h.p. per hour, there should be no difficulty in providing $4 \mathrm{sq}$. ft. of cooling surface per cylinder, making a total of $16 \mathrm{sq}$. ft. for the engine, which, acoording to the author's figures, should be adequate with a wind velocity of 30 miles per hour, which velocity could be provided with a fan absorbing not more than 1 per cent of the engine output. It is likely that more trouble will be experienced with over-cooling the motor car engine than with overheating.

Prof. F. C. Lea: The author has dealt with two issues, first, the application of light aluminium alloys to the internal combustion engine, and next, the application of these engines to the automobile. There seems to be a considerable amount of misapprehension as to the possibilities of aluminium alloys. There does not appear to be any very sound theoretical reason why an aluminium alloy should have any very considerable advantage over steel in connection with air cooled engines from the point of view of heat conductivity, because for the same strength the aluminium must be thicker. The heat conductivity to the cooling fluid is inversely proportional to the thickness, but I think the author puts his finger on an important point when he says that although the aluminium must be thicker, it does give the possibility of getting a more equable distribution of temperature in the cylinder head, and that is a point which cannot be too much emphasised. If the head of the engine is to be kept really cool sufficient cooling surface must be provided, and in the design which was produced at the R.A.E. for an air cooled aluminium cylinder there are certain very good points, the valves being carried rather high in the combustion head, and every opportunity is given for the heat to be taken away from the neighbourhood of the exhaust valves, at any rate. Another point referred to by the author is the change which takes place in aluminium alloys with time under the influence of temperature known as "growth." Again, I think this is a point which has been emphasised far too 
(Prof. F. C. Lea.)

much. Of course, everybody knows that cast iron grows, and aluminium grows to a certain extent, but only to a very minor extent-small indeed as compared with its coefficient of expansion, and the possibility of getting large differences of temperature such as $100^{\circ} \mathrm{C}$. between the piston and the liner would be very much more important in its effect than any growth taking place in the aluminium. In attempting to use such alloys in automobile work, designers must recognise that aluminium is a material with a comparatively small range in repetition stresses, not more thian plus and minus 3 to 4 tons per square inch.

Mr. A. E. Parnacotr: Mr. Bradshaw has mentioned to-night that the difficulty is not that of losing heat fast enough. I suppose really the engine should be viewed from the point of view that we can lose heat too fast; we should, however, lose it fast enough to prevent the engine overheating so as to get valve durability when these cars go out into the hands of the public.

Mr. R. H. Pearsall: On the first page the author gives the cooling power of the draught in terms of the speed. May I ask, is that speed the wind tunnel speed or is it the free speed of the surrounding atmosphere?

Dr. Gibson: The wind tunnel speed.

Mr. Pearsall: In Table IV., the author gives temperatures. I presume that these temperatures are measured at different points round the cylinder and that the mean temperature is taken.

Dr. Gibson: Yes, that is so.

Mr. Pearsall: Can the author tell us how he measured that temperature. On page 257 he refers to the different effects of petrol and benzol, and I should be much interested if he could tell us if he noticed any effect on the exhaust valve when using benzol instead of petrol. On page 260 he gives different mixtures of aluminium alloys and some of their properties. I am familiar with the properties of alloys similar to B17 but without the manganese. What is the effect of manganese on the strength at the higher temperatures? With regard to the question of miles per gallon and ton-miles, may I suggest that the ton-mile basis is very unfair to the small car, because necessarily a small car has very much greater windage per ton than the large car and I think it would be fairer to speak of gallons per passenger mile. That is really what the car user buys. Mr. Bradshaw mentioned the question of cylinder distortion. I tested a cylinder recently in which there was great trouble through the piston binding. It 
was a 3-inch piston and the distortion caused great loss of power, even when the piston clearance was $1 / 100$ inch. That was a side by side valve engine and was a very bad case.

Mr. F. A. S. Acres: The author has shown us that air-cooling can do all that is required under a fixed set of conditions. Speaking, however, from the point of view of a designer who has to produce an article for the general public, I foresee one serious difficulty, and that is with the class of driver who expects his car to climb everything on top speed. We know from bitter experience that we have more complaints of overheating from this source than from all others put together. This, of course, is due to the fact that the throttle is kept full open for prolonged: periods with an insufficient air displacement, since fan speed is proportional to engine speed, and it would appear that in the case of an air cooled engine this trouble would be considerably increased since surplus heat must be idelalt with at once, while in the case of the water cooled engine we have what Mr. Remington has called a heat flywheel. If it were not for such troubles as these we should in all probability all be using air cooled engines by now. To my mind the only method of overcoming such troubles, which arise entirely from the personal equation, would appear to be some form of thermostatic control of fan speed or fan output, which would have the further advantage that an engine which is efficiently cooled at full loads would not be overcooled at light loads as is now the case.

Mr. G. H. Lanchester: A few participants in this discussion seem to have interpreted my contribution as being pessimistic towards air cooling. It was my intention to show designers some of the difficulties rather than the rosy aspect of it. Mr. Bradshaw mentioned that he would like to dispel my pessimism by taking me up a certain hill on his car. The cars I spoke of were those that have been in the publio hands, past and present, not those that are just making their debut. The same applies to the car upon which Mr. Fedden said he would like to take me up Porlock and Lynton and Lynmouth. I wish here to state that I have driven up those hills many times on the old $10 \mathrm{~h}$.p. air cooled Lanchester with cast iron fins without overheating. What overheats an air cooled engine is the long more or less straight hill between low ranges of mountains, in which the wind may be travelling up hill at car speed or thereabout. Porlock, Lynton and Lynmouth do not come into this category. Mr. Fedden also 
(Mr. G. H. Lanchester.)

mentioned that he gets 36 ton-miles per gallon. The $10 \mathrm{~h} . \mathrm{p}$. air cooled Lanchester used to average from 39 to 42 ton-miles per gallon. It was not my intention to advertise that car, but $\mathrm{Mr}$. Fedden's remarks force me to put a good word in for the old pioneer. I should like to corroborate Prof. Lea's remarks on the growth of aluminium. I have found that for pistons the growth is negligible if the castings are properly treated.

Mr. W. H. Beauchamp: I should like to ask the author if he has any information regarding the effect of the state of the cooling medium. I refer principally to the humidity of the atmosphere, as I believe that air cooling troubles are experienced with dry air, even at a low temperature, which would not occur if the atmosphere contained a certain amount of moisture. I should be glad to know if I am correct in this surmise, and also. if there are any available data on the subject.

Mr. A. A. Rowse: Unfortunately for the success of the air cooled engine in the hands of the general public, the latter have been so spoilt by the perfection achieved by the water cooled engine in motor cars, that they will be impatient of the troubles incidental to the use of the air cooled engine, however interesting these might be to engineers.

A question which has to be considered, is the relative cost of the air and water cooled engines. Comparing the single lineahead engine of the usual water cooled type, with a similar air coolerd engine, all that is saved is the radiator, and a certain amount of the cost of the cylinder block, which latter item is closely bound up with the amount of scrap made in the manufacture. The cost of the radiator may roundly be put at $2 \frac{1}{2}$ per cent of the chassis cost. The saving on the cylinder block would be problematical, but in all probability not more than another $2 \frac{1}{2}$ per cent, and against that there will be the extra cast of the special cooling arrangements. The balance, probably less than 5 per cent, has to be set against the undoubted advantages of water cooling.

It seems to me that it is one thing to design air cooled engines: that will run satisfactorily, and another to get them taken up by the general public, which, after all, is the final test of success.

Professor Grbson, in replying on the discussion, said: I would like to take this opportunity of expressing my sense of in- 
debtedness to Major Green who, as Engineer in charge of Design, was largely responsible, along with Lt.-Col. O'Gorman and Capt. Wilkinson, for the initiation of the work on air cooling at the R.A.F. But for the faith in the possibilities of air cooling shown by these gentlemen, and but for the whole-hearted co-operation of the staff of the engine investigation department, it would have been impossible to obtain more than a fraction of the data on which the paper is based.

I would particularly like to emphasize Major Green's remarks as to the advantages of air cooling in extremes of climate. The air cooled engine will give excellent results if the mean temperature of its cooling surfaces does not exceed about $150^{\circ} \mathrm{C}$. The mean temperature of the cooling surfaces of a radiator must not exceed about $80^{\circ} \mathrm{C}$, or serious loss by evaporation will occur. If the air temperature is $0^{\circ} \mathrm{C}$., the temperature difference available for cooling is respectively $150^{\circ}$ and $80^{\circ}$ in the two cases. If the air temperature is $45^{\circ} \mathrm{C}$., as may be the case in hot climates, the differences become $105^{\circ} \mathrm{C}$. and $35^{\circ} \mathrm{C}$., so that the percentage difference in the cooling effect, with a given cylinder and a given radiator, is twice as great with water cooling as with air cooling. When the two engines are required to work under appreciable changes of altitude the result is still more favourable to air cooling.

As regards Mr. Reeves' remarks, I think the cooling of his steel cylinder with less than $0.2 \mathrm{sq}$. ft. of cooling area per horse-power on a high mean effective pressure is remarkably good, though it must be remembered that this is a central valve cylinder. The great difficulty is to cool the head of an air cooled cylinder. If a central valve is used this difficulty is greatly reduced, but the design introduces disadvantages which possibly outweigh the advantages. It is interesting to note that Mr. Reeves' figures for the horse-power absorbed in cooling, namely, 2.4 per cent of the engine horse-power, agree so well with my own.

My own opinfon as regards the relative advantages of forced versus induced fan draught is in agreement with Mr. Lanchester rather than with $\mathrm{Mr}$. Reeves. A forced draught fan handling cold air is essentially more efficient than an induced draught fan handling heated air. Moreover, with induced draught it is more difficult to prevent stream line flow over the cooling surface, and with a given air velocity, this type of air flow is much less efficient for cooling than is the turbulent motion obtained with forced 
(Professor Gibson.)

draught. If, as I believe, forced draught can be applied without complicating the design, it is undoubtedly preferable.

The Franklin car, for example, is one in which, owing to the general arrangement of the cooling, the velocity of air flow over the vital points, the cylinder heads, is very low indeed. A small alteration in the cowling would probably make a great difference in this respect.

My own experience with copper fins is similar to that of $\mathrm{Mr}$. Lanchester. Apart from difficulties in maintaining thermal contact, the copper finned cylinder is not a particularly nice proposition. The thin fins almost invariably get knocked out of shape in time and the air flow may then become seriously affected.

I quite agree that, for all but small powers, fan cooling is essential for the motor car engine. The plant must be capable of such cooling under the worst circumstances, i.e., with a following wind, as will prevent any breakdown of the lubrication, although the cylinder may then be allowed to get hotter than might be desired from a point of view of petrol consumption alone.

I was very much interested in Mr. Bradshaw's remarks on his own air cooled steel cylinders, without forced draught. As he remarks, these cylinders are operated on comparatively low mean effective pressures, which probably accounts for their freedom from overheating troubles. I think no one would advocate making cylinders of aluminium if equally good results can be obtained from steel or cast iron. The difficulty increases with the output per cu. in. of cylinder eapacity and with the size of the cylinder. If we are content to keep this low, a steel cylinder can be designed which will give good results, and possibly the motor car type of air cooled engine cylinder for small powers will ultimately be of steel or cast iron. Such cylinders will, however, always have a higher petrol consumption than a composite cylinder of equally good design, and will be more liable to overheat when the conditions are critical. My own experience tends to the conclusion that a high duty engine of the latter type can be designed to be as flexible as, and at the same time more economical than, one having iron cylinders, and for the highest class of air cooled cars of powers exceeding about $15 \mathrm{~h}$.p. I am of the opinion that such cylinders will be used.

As regards the relative noisiness of air cooled and water cooled engines, it is undoubtedly the fact that the acoustic properties of 
an air cooled eylinder are such that it tends to make a somewhat noisier engine. The difference is, however, only marked when the engine is pinking, and under normal conditions of operation, with overhead valves, with the valve rockers enclosed, comparatively silent operation can be assured.

Distortion, as pointed out by Mr. Bradshaw, is, when serious, mainly due to design. The asymmetrical $L$-headed cylinder will always be liable to this, and if only for this reason, it would appear to be advisable to concentrate on the symmetrical overhead valve cylinder where distortion is not to be feared. Regarding the effect of unduly low wall temperatures on petrol consumption, tests on water cooled engines in which the cooling water temperature was gradually reduced, indicate that with water temperatures less than about $70^{\circ} \mathrm{C}$., corresponding to wall temperatures of probably $100^{\circ}$ to $120^{\circ} \mathrm{C}$., the consumption does begin to increase slightly. This is probably caused by the increased piston friction accompanying the increased viscosity of the oil at these comparatively low temperatures.

In reply to Col. Bristow's remarks on ignition timing, in the tests in question 21 degrees was the latest timing possible. Other tests have, however, been carried out with still later timings, and have always shown that such timings give lower combustion temperatures and lower wall temperatures. As regards the rise in air temperature, this depends entirely on the velocity adopted for the cooling air and on its volume. In our tests at the R.A.E. $15^{\circ} \mathrm{C}$. has been the average rise noted.

I am grateful for Mr. Fedden's appreciation of the paper. Regarding the effect of fin roughness, I have carried out tests on a great many cylinders with the fins in the cast state, and with the fins filed and polished, but have not been able to notice any appreciable effect. At the N.P.L. a series of tests was made on smooth copper fins, which were afterwards deeply corrugated without any effect on the heat dissipation. Generally speaking, it may be taken that surface roughness has no effect if the fins are circumferential. On the other hand with longitudinal fins, for wellknown reasons the cooling is better with rough fins. I hardly agree that it is impracticable to obtain as much as $0.28 \mathrm{sq}$. $\mathrm{ft}$. of cooling surface per brake horse-power on a 6 in. cylinder, though it is admittedly not very easy to do so.

Regarding Capt. Irving's criticisms of the figures given for the petrol consumption in Table II., while I admit that these. 
(Professor Gibson.)

are not the best results which can be obtained from such engines, they were all obtained on actual tests on engines under average running conditions in Capt. Irving's own department at the R.A.E. The figures given for the petrol consumptions were not intended to indicate the best performances of either the water cooled or the air cooled engines, but were inserted to show the operating conditions under which the heat flow figures were obtained. In this connection, however, I would like to say that an examination of the "best" results obtained from all the water cooled engines tested at the R.A.E. during the war, which includes at least one example of every well-known engine, shows that the best air cooled results are at least as good as the best water cooled results, whether petrol consumption or mean effective pressure be taken as the criterion.

As regards the effect of copper deposition on steel cylinders, my own experience, based on a large number of tests, indicates that this serves no useful purpose.

Capt. Irving suggests that the behaviour of the loose aluminium head in the tests referred to in the paper indicates that even if annealed, the trouble due to warping would still have occurred. I think, however, that owing to the comparatively low temperature of the aluminium cap in operation, the "growth" would take place very slowly, much more slowly, for example, than it does in a piston, and that had the process of rebedding been repeated over a period representing, say, 200 running hours, the whole of the growth would probably have been eliminated. If this view is correct, a preliminary annealing would have removed the difficulty or reduced it considerably. Regarding the cooling of the Franklin car engine, the surface per horse-power is certainly comparatively large, but the arrangement and distribution of the cooling surfaces leave something to be desired. The comparative failure of this engine was, however, mainly due to the exceedingly small clearance in two of the cylinders, and had this been adequate, no doubt the engine would have developed a much higher horse-power before giving trouble.

Prof. Lea's remarks on alloys were most interesting. I must say, however, that I have never yet come across a cylinder head which, from a cooling point of view, I should not have liked to see thicker rather than thinner. As a matter of fact the temperature gradient in the aluminium head is so small-only about $15^{\circ} \mathrm{C}$. per $\mathrm{cm}$. in the case of the largest air cooled cylinders-that 
the difference in temperature between the inside and outside surfaces is of no moment with a head of any reasonable thickness. It may be of interest to know, in this connection, that even with all-steel cylinders it has been found necessary in practice to make the head of greater thickness than is usual in aluminium cylinders, in order to get the heat away from the centre of the head. While in the case of a piston, for example, "growth" is in general unimportant, it is very important in any case of composite construction. I have in mind one case of a steel barrel screwed into an aluminium head, where after about 25 hours' running the barrel became absolutely slack in the head and had to be removed. The head was then annealed, a new barrel was screwed in, and this gave no further trouble.

With reference to Mr. Pearsall's questions, all temperatures were measured by thermo-couples let into holes in the cylinder walls. I cannot say that I have ever noticed any effect on an exhaust valve when using benzol instead of petrol. On the whole the effect of about 1 per cent of manganese is to strengthen an alloy at high temperature as indicated by the figures for B 17 alloy in Table XIII.

Mr. Beauchamp inquired as to the effect of the humidity of the atmosphere. We have investigated this by drawing the air supply through a saturated screen, but noticed no appreciable difference as compared with air in its normal state of humidity. 


\section{COMMUNICATIONS.}

Mr. W. H. M. HighaM wrote: Whilst realising to the full the value of the paper, it seems to me a pity that some reference was not made to the cooling of engines of the two-cycle type. To my mind the future "car for the multitude" will of necessity be a combination of the two-cycle engine and air cooling, and it would appear from the paper that the science of air cooling has reached a stage of development in advance of that reached in two-cycle research.

Most writers of technical works are emphatic in stating that the air cooling of a two-cycle engine is a much more difficult matter than that of a four-cycle engine. It is certainly true that for a given number of revolutions, there are twice the number of explosions in a two-cycle engine as in a four-cycle engine, but at first sight overheating would not be expected in the two-cycle engine, owing to the low brake mean effective pressure obtaining, and the fact that the engine is partially cooled internally by the cool mixture in the crankcase. This, unhappily, does not agree with the experiences of a large proportion of owners of air cooled two-cycle engines, and it is typical of the difficulties that would appear to arise when we see that one of the most successful types of motorcycle engine is water cooled, having been tried with air cooling and found wanting.

If, however, we refer to Table IV. in the paper, we find that the mean temperature of the cylinder barrel decreases with an increase in the mean effective pressure up to the point where "pinking" occurs. If the converse holds good, it seems to explain why the small inefficient two-cycle engine suffers from overheating when run "all out" for a long period. Perhaps the author will correct me if my assumption is wrong.

Before leaving the question of two-eycle engines, it would be interesting to hear the author's views on cylinder distortion, which is commonly supposed to be a greater evil than in four-cycle engines. As he has banished the bogey of bad cylinder distortion in the overhead valve aero engine, can he reassure us to the same extent about the two-cycle engine, and say, whether remedies such as embodying exhaust ports and transfer passages in a com- 
paratively heavy section aluminium casting in order to equalise the heat distribution are really necessary?

Reverting to the four-cycle engine, it would be interesting to have the author's opinion as to whether he considers the air cooling of stationary paraffin or other oil engines a commercial possibility. In this case, as far as my experience goes, abnormally high-or even car engine standard - compression ratios cannot be used. One of the most successful paraffin electric lighting seto built and used has in the larger sizes, say, from 30 to 40 h.p., only 30 to $40 \mathrm{lb}$. compression pressure, with a bore of $6 \frac{3}{4} \mathrm{in}$. Higher compression ratios in this engine lead to pre-ignition, owing to overheating of valves. In paraffin engines of this type, the explosive mixture is very hot when taken into the cylinder, and as a result the inlet valve is kept at approximately the same temperature as the exhaust valve. The eylinder is of normal L-head design, and generously cooled on the thermo-syphon system. Would it be practicable to cool such an engine by means of a fan flywheel, on the same principle as a well known American lighting set, which is also of abnormally low compression, but in addition of small bore? The air velocity past the cylinder in the aase of the latter is approximately $20-30$ miles per hour at 1,000 revs. per minute.

I am aware that this last does not come under the heading of automobile practice, but judging by the trend of events, it would seem as if we should have to look to other fuels oheaper than petrol for car propulsion, with correspondingly different conditions of running.

Alcohol would appear to lend itself admirably to air cooling. Has the author any data on the subjeot?

In reply to the written communication, Prof. Gibson wrote: With reference to the interesting points raised by $\mathrm{Mr}$. Higham, the two-cycle engine is essentially more difficult to cool than the four-cycle type, since the heat to be dissipated from a given size of cylinder is approximately 50 per cent greater in one case than in the other. While this is the case, the margin of cooling which is available with four-cycle cylinders of small bore-up to say 4 in. -with a reasonable air draught is so large, that there should be no difficulty in air cooling two-cycle cylinders up to this size. I know of one experimental aluminium two-cycle engine of $80 \mathrm{~mm}$. bore which has been operating with great success on the road for GIBSON. 
(Professor Gibson.)

some months now. It shows maximum temperatures which have never been known to exceed $250^{\circ} \mathrm{C}$., and never "knocks." I think Mr. Higham is quite correct in his assumption regarding the connection between mean effective pressure and tendency to pink.

Regarding distortion, I do know that this particular cylinder has never given any trouble, and am convinced that it only needs reasonable care in design to make the two-cycle engine as free from trouble in this respect as the four-cycle engine.

I have had very little experience with the use of paraffin in small engines, but can confirm Mr. Higham's remarks as to the necessity for keeping the compression ratio low with paraffin as a fuel. Still, since it is possible satisfactorily to air cool a cylinder using petrol having a diameter of 8 in., and developing a mean effective pressure exceeding $100 \mathrm{lb}$. per sq. in., and since the difficulty of cooling is essentially greater as the diameter increases. I cannot see any reason why, given a reasonable air blast, any cylinder using paraffin, say up to $6 \mathrm{in}$. in diameter, should not be satisfactorily air cooled.

I have had some experience with the use of alcohol. While the compression ratio requires to be higher than with petrol, the amount of heat per brake horse-power given to the cylinder walls is slightly less with alcohol, and the cylinder is in consequences more easily cooled. The air cooled alcohol engine would be a decidedly attractive proposition. 